\title{
Mapping Regional Inundation with Spaceborne L-Band SAR
}

\author{
Bruce Chapman ${ }^{1, *}$, Kyle McDonald ${ }^{1,2}$, Masanobu Shimada ${ }^{3}$, Ake Rosenqvist ${ }^{4}$, \\ Ronny Schroeder ${ }^{1,5}$ and Laura Hess ${ }^{6}$
}

1 Jet Propulsion Laboratory, California Institute of Technology, Pasadena, CA 91109, USA

2 CUNY Environmental Crossroads Initiative and CREST Institute, The City College of New York, City University of New York, New York, NY 10031, USA; E-Mail: kmcdonald2@ccny.cuny.edu

3 Earth Observation Research Center, Japan Aerospace and Exploration Agency, Tsukuba 305-8505, Japan; E-Mail: shimada.masanobu@jaxa.jp

4 SoloEO, Tokyo 305-8505, Japan; E-Mail: ake.rosenqvist@soloEO.com

5 Institute of Botany, University of Hohenheim, D-70593 Stuttgart, Germany;

E-Mail: ronny.schroder@gmail.com

6 Earth Research Institute, University of California, Santa Barbara, CA 93106, USA;

E-Mail:1ola@eri.ucsb.edu

* Author to whom correspondence should be addressed; E-Mail: bruce.d.chapman@jpl.nasa.gov; Tel.: +1-818-354-3603; Fax: +1-818-393-3077.

Academic Editors: Alisa L. Gallant and Prasad S. Thenkabail

Received: 6 November 2014 / Accepted: 13 April 2015 / Published: 30 April 2015

\begin{abstract}
Shortly after the launch of ALOS PALSAR L-band SAR by the Japan Space Exploration Agency (JAXA), a program to develop an Earth Science Data Record (ESDR) for inundated wetlands was funded by NASA. Using established methodologies, extensive multi-temporal L-band ALOS ScanSAR data acquired bi-monthly by the PALSAR instrument onboard ALOS were used to classify the inundation state for South America for delivery as a component of this Inundated Wetlands ESDR (IW-ESDR) and in collaboration with JAXA's ALOS Kyoto and Carbon Initiative science programme. We describe these methodologies and the final classification of the inundation state, then compared this with results derived from dual-season data acquired by the JERS-1 L-band SAR mission in 1995 and 1996, as well as with estimates of surface water extent measured globally every 10 days by coarser resolution sensors. Good correspondence was found when comparing open water extent classified from multi-temporal ALOS ScanSAR data with surface water fraction identified from coarse resolution sensors, except in those regions where there may be differences in sensitivity to
\end{abstract}


widespread and shallow seasonal flooding event, or in areas that could be excluded through use of a continental-scale inundatable mask. It was found that the ALOS ScanSAR classification of inundated vegetation was relatively insensitive to inundated herbaceous vegetation. Inundation dynamics were examined using the multi-temporal ALOS ScanSAR acquisitions over the Pacaya-Samiria and surrounding areas in the Peruvian Amazon.

Keywords: SAR; wetlands; ALOS; inundation; double-bounce

\section{Introduction}

The lakes, rivers, and wetlands of the lowland Amazon Basin span at least 800,000 square kilometers [1,4]. Each year the runoff from heavy seasonal rains causes extensive and prolonged flooding of vegetated environments. These seasonally, semi-permanently or permanently inundated areas, in addition to forming biologically diverse habitats, also regulate biogeochemical processes such as the generation of methane and the outgassing of $\mathrm{CO}_{2}$ [2-5]. The flooding dynamics will also be impacted by any future changes in rainfall and evapotranspiration; some global circulation models predict that annual rainfall rates in the Amazon Basin could decrease substantially in the next several decades (e.g., [6,7]). The ability to accurately monitor changes in inundation extent, including uncertainties and possible biases, would support the study of possible climatological tipping points in regions where extensive inundation is prevalent [8].

Earth's globally distributed wetlands are the largest natural sources of methane. However, extensive disagreements exist between wetland maps and available remotely sensed inundation data sets, in particular those that specifically target the extent of vegetated wetlands. Of particular note for global methane modeling, saturated non-inundated wetlands are also important, given that many wetlands will continue producing methane at depth even if there is no standing water [5].

The flooding dynamics of the wetland areas be can difficult to study by traditional optical remote sensing techniques due to frequent cloud cover and the difficulty of detecting sub-canopy inundation $[9,10]$. One alternative approach is to use a suite of complementary satellite measurements to estimate factional extent of inundation at a coarse scale [11]; however, these data sets necessitate the masking of non-wetland areas and could have difficulty detecting inundated areas under the dense forest canopies in tropical regions [5]. One recent technique consists of using very coarse resolution gravity data from the National Aeronautics and Space Administration (NASA) Gravity Recovery and Climate Experiment (GRACE) mission in combination with satellite altimetry data and other sources of data to estimate the volume of water filling and draining from large wetlands [12,13]. Perhaps, the best results for the detection of inundated vegetation and open water at fine resolution scales and on large regional scales (though not yet global) have been obtained through the use of Synthetic Aperture Radar (SAR) polarimetric backscatter data (e.g., [2,9,14-18]). An important feature of SAR is that cloud cover is irrelevant to the detection of inundation, and SAR technology therefore allows for a detailed examination of the seasonal dynamics of the flooding extent at resolutions better than $100 \mathrm{~m}$.

We will describe the development of regional-scale moderate-resolution inundation products based on space-borne L-band Synthetic Aperture Radar (SAR) data from the Japan Aerospace Exploration 
Agency's (JAXA) ALOS PALSAR instrument. ALOS PALSAR data were provided to this task through an international science program led by JAXA called the Kyoto and Carbon (K\&C) initiative. The objective of the $\mathrm{K} \& \mathrm{C}$ Initiative is to support data and information needs of international environmental conventions, carbon cycle science, and conservation of the environment. The initiative established a global systematic observation strategy for ALOS PALSAR that includes repetitive and consistent mapping of the world's major wetland regions [19]. For several years, the K\&C Initiative was based on three coordinated themes relating to global biomes (Forests, Wetlands, Deserts and Semi-Arid Regions), and a fourth theme dealing with the generation of regional ALOS PALSAR mosaics. One of the motivations of the mosaicking theme lies in the historical context of the Global Rain Forest Mapping project (GRFM) [19] in which JERS-1 SAR imagery from selected forest areas around the globe (Southeast Asia, Amazon Basin, Africa, Boreal North America) were calibrated and mosaicked for further use by the scientific user community.

Since the GRFM project, there have been several technology enhancements that made mosaic generation more straightforward: path processing of the image strips, reductions in cost of resources, improved position accuracy for the ALOS satellite, and the existence of a near global high resolution Digital Elevation Model (DEM) from the Shuttle Radar Topography Mission (SRTM) for ortho-rectification and calibration [20].

The results of this work, funded by the NASA Making Earth System Data Records for Use in Research Environments (MEaSUREs) program office, are to become part of an Earth Science Data Record (ESDR) documenting inundated wetlands.

\section{Methodology}

The production of regional scale inundation products required the following processing steps: accurate orthorectification of the data, radiometric terrain correction, relative and absolute calibration corrections, image mosaicking, and image classification. Many of the described processing steps are CPU intensive. To facilitate the processing of these data, in particular the ortho-rectification of the data, some processing was conducted at the NASA Advanced Supercomputing Division located at the NASA Ames Research Center (NASA Ames, 2014) [21].

\subsection{Description of Satellite Data}

ALOS PALSAR, an orbiting L-band SAR launched by the JAXA in 2006, pursued a global observation strategy through the mission's end of life in April 2011. By restricting both the mode and the look angle for many of the observations, a time sequence of regionally consistent imagery was produced [22]. Here, results will be shown from using ALOS PALSAR while it was operating in ScanSAR mode. When in ScanSAR mode, ALOS PALSAR had a swath width up to a $350 \mathrm{~km}$, a resolution of $100 \mathrm{~m}$ with three looks, and a noise equivalent $\sigma^{\circ}$ better than $-23 \mathrm{~dB}$ [23].

During orthorectification and radiometric calibration of the ALOS ScanSAR data, the DEM generated by the SRTM mission was utilized. There are several processing versions available for the SRTM DEM, but this study used SRTM processing version 2.1 [24]. In South America, the pixel spacing was 3 arcseconds, which corresponds to about $90 \mathrm{~m}$ at the equator. Vertical height accuracy of this DEM was found to be better than $7 \mathrm{~m}$ in South America [25]. 
JERS-1 SAR was an L-band SAR launched by Japan Aerospace Exploration Agency (then known as "NASDA") in 1992 and discontinued operations in 1998. The HH polarization SAR imaged the Earth at an incidence angle centered at 35 degrees, and at its full resolution of $18 \mathrm{~m}$ the data had three looks. Its noise equivalent $\sigma^{\circ}$ was $-18 \mathrm{~dB}[26]$.

AMSR-E was a dual-polarized total-power passive microwave radiometer provided by JAXA with 12 channels and six frequencies ranging from 6.9 to $89.0 \mathrm{GHz}$. It was launched onboard the Aqua satellite and discontinued operations in October 2011. The instrument was designed to measure precipitation, oceanic water vapor, cloud water, near-surface wind speed, sea surface temperature, soil moisture, snow cover, and sea ice parameters [27,28].

\subsection{Orthorectification and Radiometric Terrain Calibration}

Orthorectification of the data consisted of resampling the geocoded slant range data into a well-known projection and file format. SAR image radiometry is impacted by topographic slope. This terrain-induced change in backscatter can mimic the signature of inundated wetlands in areas where there should be no inundated wetlands (i.e., hilly terrain). It is well known how to correct the radiometry of the image for this effect, but it requires that the imagery be well registered to the topographic data (e.g., [29]). In addition, the elevation of the ground impacts the geometric translation of the slant range imagery when projected onto the topographic model of the Earth.

The JAXA Earth Observation Research Centre (EORC) provided ScanSAR mode slant range image strips for use by the science team of the ALOS K\&C Initiative. These ScanSAR image strips were typically thousands of kilometers in length, but have reduced resolution compared to that obtained during standard processing. JAXA refers to these image products as "path" image products [30].

First, topographic data were constructed from the publicly available SRTM DEM. Since the image strips extend across continental-scale regions, we created SRTM-like "tiles" of topography information corresponding to Universal Transverse Mercator (UTM) zone definitions, each tile therefore being approximately $6^{\circ} \times 8^{\circ}$ in size. The tiles are reconstructed from the SRTM data to be slightly larger than the strict UTM zone definition to accommodate edge effects. These tiles remained in the standard SRTM projection, a rectangular latitude/longitude grid with a pixel spacing of 3 arcseconds. Since the ScanSAR path image products have a spatial resolution of approximately $100 \mathrm{~m}$, the resolutions of the DEM and ScanSAR imagery are roughly comparable.

For orthorectification and radiometric terrain correction, a software package from Gamma Remote Sensing [31] was employed. Each processed path image was projected onto the DEM of each UTM zone that it passed through. To correct residual geolocation errors, the Gamma Remote Sensing package includes software for well-known techniques for estimating and correcting offsets between images [32]. This software is designed to assist in co-registering pairs of SAR images prior to interfering them, but also can be used to correct the image geocoding parameters.

Wetland areas in our study regions are challenging, as they are highly dynamic. The rivers and wetland areas frequently change in appearance and sometimes slightly in location. However, we found that cross-correlating the imagery against a SAR image based on the SRTM DEM (i.e., as described in [33]) can be effectively used to determine geocoding errors. 
The range and azimuth offsets sampled from 388 UTM grid-zone-projected images prior to correction were examined (see Figure 1). The mean range offset was found to be -0.22 pixels in range, and -0.54 pixels in azimuth, with a standard deviation of over 4 pixels. If we exclude outliers from one particular orbit path in which the offsets were consistently greater than 10 pixels, we found that the mean range offset was 0.34 pixels and the mean azimuth offset was -0.22 pixels, with a standard deviation of about 2 pixels. The range spacing for the path images was 37.5 meters in range and $70 \mathrm{~m}$ in azimuth, which led to a mean range offset of $12.8 \mathrm{~m} \pm 82.5 \mathrm{~m}$, and a mean azimuth offset of $-15.4 \mathrm{~m} \pm 119 \mathrm{~m}$ (excluding RSP424). Although the mean offset was quite small, the offset for each image was not a simple overall range and azimuth shift, but a varying shift in both range and azimuth. To compensate for this variability, a standard 6th order polynomial was fit to the varying range and azimuth offsets and used to correct the varying shift for each UTM grid-zone-projected path image.

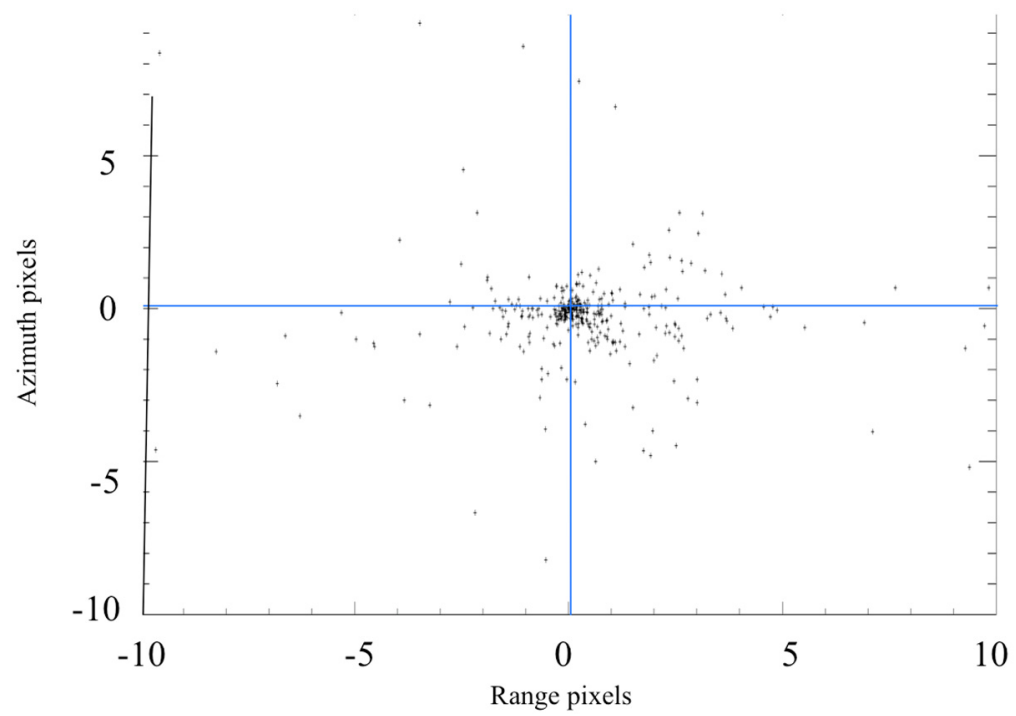

Figure 1. Mean offsets of 388 UTM grid-zone-projected path images from SRTM DEM.

Once the data were accurately geocoded with respect to the UTM grid-zone tiles, the radiometric terrain correction could be applied. The objective of the radiometric terrain correction is to determine the normalized radar backscatter $\gamma^{\circ}$ in the ground plane from the slant range $\sigma^{\circ}$ imagery provided by JAXA. The following equation was implemented by a set of code from Gamma Remote Sensing:

$$
\gamma_{x, y}^{\circ}=\sigma_{x, y}^{\circ} \times A_{x, y} \times \cos \left(\theta_{\text {mid }}\right) / \cos \left(\theta_{x, y}\right)
$$

where $\gamma_{x, y}^{\circ}$ is normalized, terrain-corrected radar backscatter for each pixel $(x, y) ; \sigma^{\circ}, y$ is the ground projected sigma-naught values from JAXA for each $(x, y)$ ground pixel; $\theta_{\text {mid }}$ is the mid-swath incidence angle used by JAXA when calculating the original sigma-naught image; $\theta_{x, y}$ is the local incidence angle at each $(x, y)$ ground pixel; and $A x, y$ is the pixel size normalization factor for each $(x, y)$ pixel calculated from the projection angle, which is the angle between the surface normal and the image plane normal. Note this correction is only effective if we have an accurate assessment of the slope of the imaged terrain. Radiometric errors due to sub-pixel topographic slope variability cannot be corrected. 


\subsection{Relative and Absolute Calibration}

Although the data have been generally corrected for radiometric error due to measured slope, errors in relative and absolute calibration remain in the imagery. Relative calibration errors are generally visible as brightness trends in the along-track or cross-track directions. Absolute calibration errors are absolute offsets that are noticeable when examining a temporal sequence of images from the same orbit geometry and observation mode.

There were several empirical approaches taken to correct for these remaining radiometric errors. When we use an empirical approach during calibration refinement, we must make some assumptions that may on occasion be violated. Some environmental conditions will result in changes in radar-backscattered brightness, and these changes in brightness may be incorrectly interpreted as calibration errors. When these "calibration errors" are "corrected", the resultant imagery will actually be obscuring a real physical change in radar brightness. However, we chose to enforce consistent radiometry across the multi-temporal sequence of SAR images to more robustly enable the detection of inundation. Fortunately, the signatures of inundation, open water and inundated vegetation, are generally quite distinct from second order radiometric changes caused by physical changes in the environment such as changes in moisture content.

When calibrating the long path image strips from the JAXA EORC path image product, we also must assume that the relative calibration accuracy may vary in both the along-track and cross-track direction. We must therefore take care to insure that the average calibration correction applied to any given image is $0 \mathrm{~dB}$, so as not to introduce absolute calibration errors when calibrating relative calibration errors. The most common relative calibration error that required correction was visibly apparent as "banding" in the radiometry, typically aligned in the cross-track direction. Absolute calibration errors were evaluated by comparing individual images with the average image brightness of the multi-temporal stack of images $I_{a}$, then comparing with the radar image brightness in adjacent UTM grid zones; sometimes several iterations of calibration were required before the imagery converged to a stable value.

Two simple methods were used to identify and evaluate absolute calibration errors. First, the ortho-rectified image segments can be stitched into a single image to form a mosaic. There are several available options for deciding which pixel from multiple images is preserved in the mosaic when a location on the ground is imaged in more than one pass. The option we chose was to have the far-range portion of the imagery take precedence over the near range-imagery. We chose this option because the backscatter from open water can be more variable in the near range due to wind roughening of the water surface. We ignored zero-fill areas. Second, after a mosaic is constructed, it sometimes is visibly apparent that adjacent images have a significant difference in brightness. This manifests as a banding effect within the mosaic and may make it problematic to correctly classify the status of inundation in wetland areas. We therefore compared individual orthorectified image strips with the average image brightness of all the images within the UTM grid-zone, then performed the adjustments described below.

The image brightness can vary for a variety of reasons. In addition to environmental factors, the instrument calibration may be in error, or there may be processing errors introduced at some stage. Given that the radar backscatter of targets varies with incidence angle and with target type, and given that ScanSAR data have a wide range of incidence angles within a swath (from $20^{\circ}+$ to $40^{\circ}+$ ), some banding may be due to the varying nature of the scattering of whatever is on the ground. Recent changes in 
moisture content of vegetation and/or ground soils can result in significant changes in backscatter as well [34]. In the context of making it easier to identify locations of inundated wetlands, this change in brightness, whatever its cause, can be compared with adjacent images or an image average, and an empirical adjustment performed. This may, however, obscure physical signatures in the data. Changes in backscatter texture and contrast due to some of these effects, in particular those due to varying incidence angles within an image, cannot be easily corrected.

To examine this phenomenon more fully, 70 ScanSAR image strips were analyzed from UTM grid-zone tile $19 \mathrm{M}$ in South America. For each pixel in the tile, the mean and standard deviation of the radiometrically corrected backscatter values were calculated, as well as the ratio of the standard deviation to the mean. If this ratio was less than 0.3 (which we found by observation typically indicated that the pixel was not predominately open water or occasionally inundated vegetation), the mean difference between the mean value and the individual value was determined. For these 70 ScanSAR image strips within tile $19 \mathrm{M}$, millions of pixels satisfied this criterion. The average mean-difference for each ScanSAR image strip was then calculated and plotted as a function of acquisition date (Figure 2).

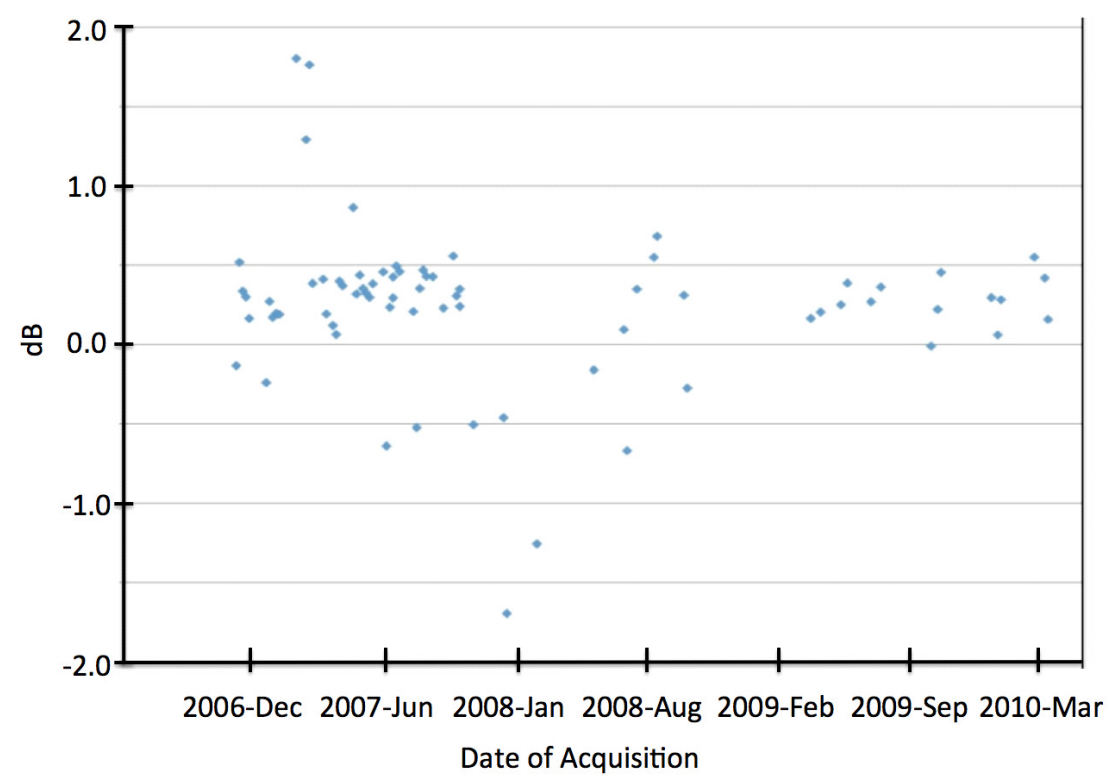

Figure 2. Average mean-difference between average image brightness and each of 70 ScanSAR image strips in UTM grid-zone tile 19M.

As can be seen from Figure 2, the mean difference typically varied less than $0.5 \mathrm{~dB}$, with occasional divergence of almost $2 \mathrm{~dB}$. For each UTM grid zone, the temporal sequence of imagery was examined for each path, and when necessary, an empirical correction to the absolute calibration was applied. Images from adjacent UTM grid zones were then visually compared to insure that systematic bias was not introduced.

We expected that these radiometric and geometric terrain correction as well as other calibration adjustments when applied to the ALOS PALSAR data provide a more robust calibrated product for classification of inundation. 


\subsection{Mosaicking}

Mosaicking involves combining together orthorectified and calibrated image products into a single calibrated image product. Evaluation of the image mosaic products is helpful for determining processing and acquisition gaps, identifying residual calibration errors, visualization of the data, and inundation product development. For this work, we produced a multi-temporal image mosaic for the entire study region of South America, where each pixel on the ground represented the average of all SAR image pixels for that location on the ground. The advantage of this type of mosaic is that it represents a time-averaged history of each image pixel. Even if the temporal sampling interval is erratic, if the time sequence is long enough, the average brightness will be representative of the typical state of that pixel. The impacts of random calibration errors in the individual image segments are reduced through the averaging process. The disadvantage of this type of mosaic is that the actual temporal uniqueness of each SAR image is lost, as well as variation due to incidence angle. However, if the individual image segments are preserved as well, it is still possible to temporally track environmentally distinguishable changes. One advantage of all mosaicked products is that mosaicking eliminates overlapping coverage, simplifying the interpretation of the imagery.

A Basic Observatory Strategy (BOS) for ALOS PALSAR was implemented by JAXA to facilitate temporally consistent acquisitions of data by PALSAR [22]. The BOS allocates the ALOS observations within its 46-day orbit cycle such that certain combinations of regions and modes were given high priority for scheduled observations. However, the success rate for this strategy varied slightly by region, mode and time period.

To quantify the typical success rate, we examined intervals between successive ScanSAR acquisitions, where the intent was to image each pixel at least once every 46 days for a randomly selected $1^{\circ}$ by $1^{\circ}$ area in South America (coordinates $7^{\circ} \mathrm{S}, 65^{\circ} \mathrm{W}$ ) over an 18 -month time period. The average interval between acquisitions somewhere in this region was 33 days. However, due to scheduling and other conflicts, there was one gap of 128 days and another gap of 90 days. A total of 18 ScanSAR acquisitions crossed this zone during this time period. The temporal sampling for each ground location was uneven, despite the use of an observing strategy designed to increase the likelihood of temporally consistent observations.

Once the mosaic was constructed and calibrated from the slant range path images, a simple stitching algorithm for aggregating the UTM grid-zone tiles into a single image file could be used to obtain wider scale image mosaics. We generated multi-temporal ScanSAR mosaic of South America from 323 ScanSAR path images acquired between late-2006 and mid-2010 (Figure 3). This mosaic is a time-averaged image and, therefore, not necessarily straightforward to interpret. However, it clearly delineates areas of interest for studying wetland dynamics using the individually ortho-rectified and calibrated path images. Martinez and Le Toan [35] showed that temporal filtering plus some spatial filtering increased the equivalent number of looks for improved classification of the imagery.

Figure 4 shows the detailed appearance of the multi-temporal ScanSAR image mosaics at full resolution ( 3 arc seconds, or approximately $100 \mathrm{~m}$ ). Due to the higher number of looks at each pixel, the image contrast is high compared to individual ScanSAR image swaths, and often makes it possible to clearly distinguish open water from sparsely vegetated areas and low-stature vegetated areas (which we will henceforth call "low vegetated areas"), and different gradations of vegetation density and height, 
as well as clearly signifying those areas that experience inundation during some of the ALOS PALSAR acquisitions.

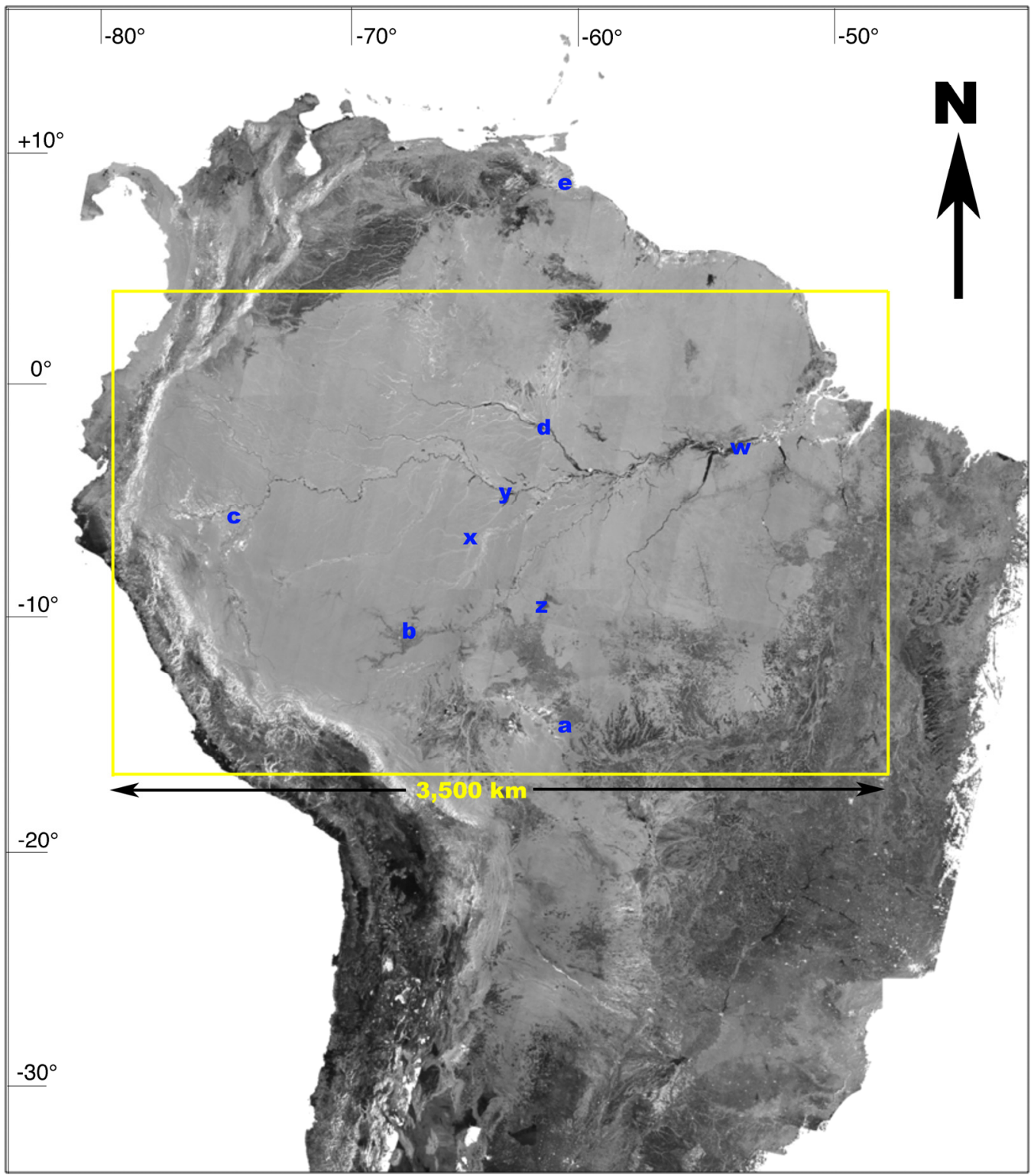

Figure 3. Orthorectified ScanSAR mosaic of most of South America, late-2006 to mid-2010. Colored letters correspond to details shown in subsequent figures. C JAXA,METI.
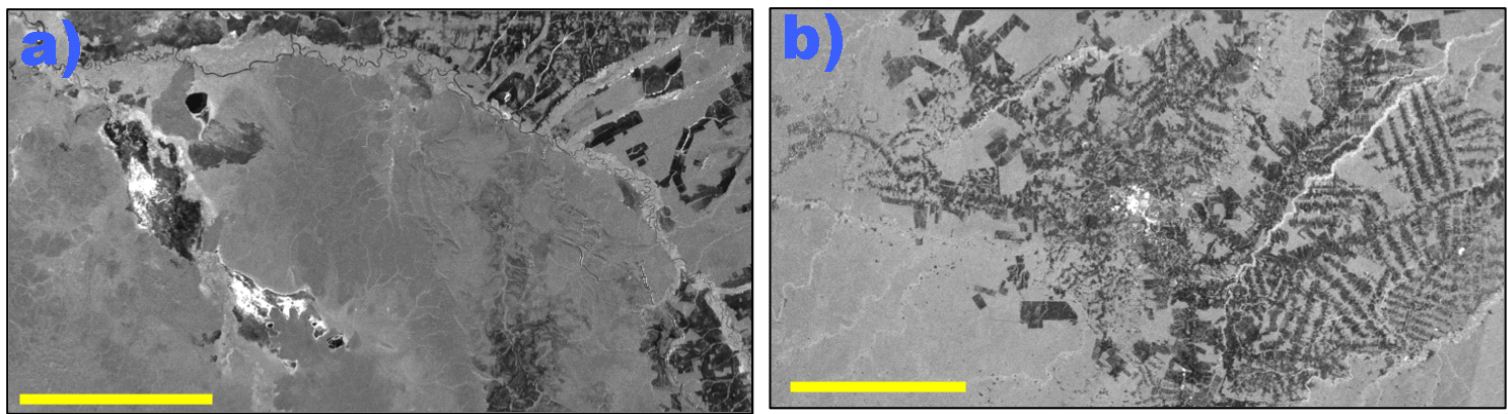

Figure 4. Cont. 

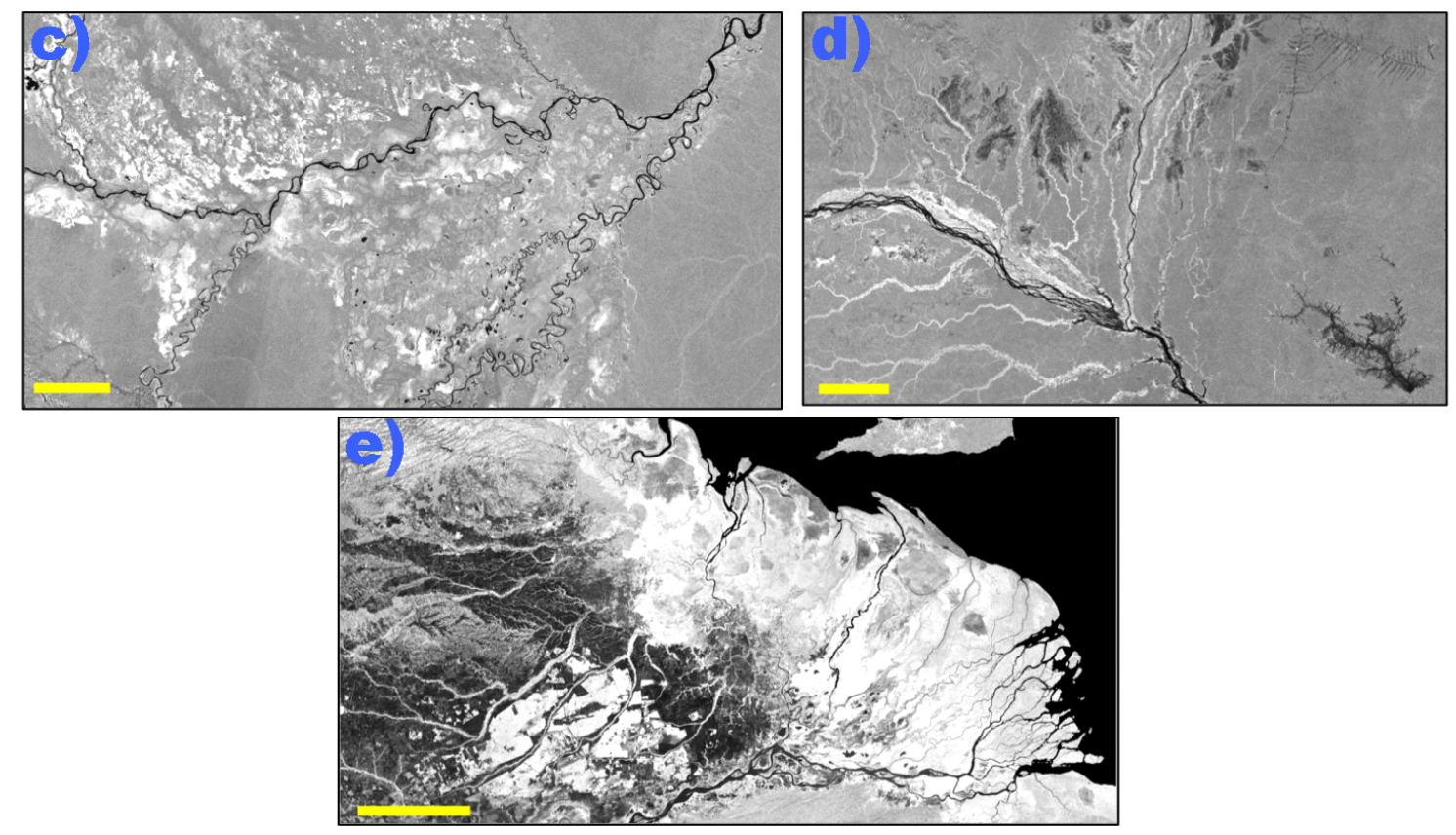

Figure 4. Yellow scale bar corresponds to $50 \mathrm{~km}$, and the location of each sub-figure is shown in Figure 3. Generally, we may associate the brighter areas as caused by double-bounce reflections in inundated vegetation areas or urban regions. Water and bare soil appear dark and forest areas are medium-grey shades. Locations are indicated in Figure 3. (a) Noel Kempff National Park, Bolivia; (b) Deforestation near the city of Rio Branco, Brazil (bright area at center) and inundated Iquiri River floodplain; (c) Pacaya-Samiria Reserve, Peru; (d) middle Rio Negro; and (e) Orinoco Delta. C JAXA, METI.

\subsection{Image Classification}

The mechanisms responsible for the detection of inundation by L-band SAR are well known (e.g., [2,9,14,17,18,35]). Microwave energy scatters off open water, generally specularly reflecting off of the smooth water surface away from the radar. The resulting radar backscatter is low. Wind roughening can cause the backscatter from inland waters to increase, brightening the radar image. Where it is possible to choose from a catalogue of images, giving preference to those that imaged the target from larger incidence angles can often minimize this problem. Radar parameters such as the Signal to Noise Ratio (SNR) can affect the ability to distinguish open water from other dark targets such as bare ground. However, in general it has been found possible to identify open water in L-band radar imagery (e.g., [36]) due to the specular scattering mechanism. More interesting is the ability to distinguish inundation beneath a vegetation canopy. The microwaves transmitted by the radar, especially horizontally polarized radiation, scatter off both the flat open water surface and the vertically emerging vegetation (i.e., a "double-bounce" reflection). The latter results in a large fraction of the transmitted power being reflected directly back to the radar. The penetration by the microwaves through the overlying vegetation canopy can be quite effective and, despite volume scattering by the vegetation canopy and attenuation of the radar signal by the vegetation canopy, there is a strong return back to the radar. However, inundated vegetation is not the only landscape feature that results in double-bounce reflections. For instance, urban areas often exhibit double-bounce reflections off streets and vertically 
oriented building structures (when the street is oriented parallel to the flight track of the radar system). Additionally, double-bounce is not the only mechanism resulting in bright image returns in an HH image; an extremely rough surface such as that often found in lava flows, also may produce very bright returns.

The most common method by which scientists have been using L-band SAR data to detect inundated vegetation is through examination and classification of $\mathrm{HH}$ polarized imagery. One technique is to determine image brightness thresholds that are indicative of inundation (e.g., $[1,18])$. Other approaches employ image segmentation to classify the inundation characteristics based on characteristics of the spatially segmented region, though still dominantly based on the HH backscattered brightness [1]. Due to the extensive collection of multi-temporal ALOS ScanSAR data, we can also include the multi-temporal observations as factors in the classification of the imagery.

Our objective was to use established algorithms for identifying inundation extent. Previous work has shown that (1) certain L-band brightness thresholds identify inundation and (2) dramatic temporal changes in L-band brightness can often indicate a change in inundation state. We describe here a classification approach used to identify inundation classes in South America from ALOS PALSAR acquired between late-2006 and mid-2010 while in ScanSAR mode. Because of uneven temporal sampling, a consistent time sequence showing periodic change in inundation for the entire Amazon basin was problematic. However, we assumed that after four years of numerous, yet sporadic, ScanSAR acquisitions, each pixel area on the ground would have been imaged in all inundation states that it might experience: not inundated, inundated vegetation, and/or open water. This was similar to the approach of Martinez and le Toan [35], where multitemporal JERS-1 data were classified into several different inundation classes.

We did not attempt to explicitly identify aquatic macrophytes, as the range of L-band backscatter values that characterize floating macrophytes overlaps with other more distinct conditions. Aquatic macrophytes are believed to occupy between $5 \%$ and $8 \%$ of the wetland areas of the central Amazon Basin [1].

We first produce a multi-temporal radar backscatter image $I_{a}$, averaging the data from each acquisition, as described previously. When the terrain land cover does not change, the speckle from the individual ScanSAR images is reduced. For those areas experiencing environmental changes, the average will reflect the varying backscatter at the various time periods represented by the imagery. However, since open water and inundated vegetation are at opposite ends of the range of radar backscatter values, the average will tend to show evidence of these inundation events, especially if they are persistent.

The first step was to examine $I_{a}$, and use threshold image brightness values to determine an initial class. The threshold backscatter values were obtained from Arenson et al. [18]. Examining ALOS ScanSAR data over the Curuai Lake floodplain, Arneson et al. obtained GPS-located photographs at one-degree incidence angle intervals across a ScanSAR image swath acquired at similar water level stage as the ScanSAR data. Using Landsat-5 TM data, Arneson et al. determined land cover type. They then used image segmentation techniques, to determine the range of backscatter values corresponding with various land cover types including non-flooded forest, flooded forest, open water, bare soil, and water bodies with emergent macrophytes. These backscatter values form the basis for the threshold image brightness values that we used in determining an initial class.

We used the ESA GlobCover 2009 land cover classification product [37] sampled every $300 \mathrm{~m}$ to establish the location of urban areas that are difficult to distinguish from flooded vegetation based on radar backscatter values alone. See Table 1 for the criteria for each of eight classes. These initial classes may represent a typical land cover/inundation state for the period in question, but in areas where the 
inundation state is variable, this initial class can only represent one of the possible inundation states that those areas may experience. In addition, an area that experiences both open water and inundated vegetation conditions on average may indicate non-inundated forest or low vegetation from the averaged radar backscatter. Individual ScanSAR acquisitions must be examined to clarify the variability, where the ratio of each ScanSAR image to $I_{a}$ was used to indicate the likelihood that the inundation state found in the initial classification was variable.

Table 1. Initial class identification from multi-temporal average radar backscatter and ESA GlobCover land cover classification product.

\begin{tabular}{ccc}
\hline Initial Class & Radar Backscatter (dB) & GlobCover Class \\
\hline Urban & $I_{a}>-5.9$ & $190^{1}$ \\
Flooded vegetation & $I_{a}>-5.9$ & Any \\
Forest & $-5.9>I_{a}>-9$ & Any \\
Low vegetation & $-9.0>I_{a}>-13.7$ & Any \\
Open water/low veg or bare & $-13.7>I_{a}>-19.0$ & Any \\
Open water 1 & $I_{a}<-19$ & $210^{2}$ \\
Open water 2 & $I_{a}<-19$ & Any \\
Topographic slope mask & Any & Any \\
\hline (if SRTM height difference to adjacent pixels exceeds 18 m) &
\end{tabular}

${ }^{1}$ Artificial surfaces and associated areas; ${ }^{2}$ Water bodies.

For identifying change in inundation state from the typical (initial) classification, we needed to identify those pixels where the individual ScanSAR images indicate a change in scattering signature from that given by the initial class. As single ScanSAR images are speckled due to the small number of looks at the posted spacing, we applied a $3 \times 3$ moving average filter to these data. We refer to the ratio of these multi-looked ScanSAR image pixel values to $I_{a}$ as $\Delta b$.

If the initial class for a set of pixels was forest, the typical state of those pixels as revealed by $I_{a}$ corresponded with what we would expect in radar backscatter values for non-inundated forest. However, if one or more of the ScanSAR images was significantly brighter than $I_{a}$ in these areas it indicated there had been an increase in double-bounce scattering for those ScanSAR image dates, which we therefore identified as being associated with inundation. If the initial class was open water, and we observed a large positive $\Delta_{b}$, we assumed it was due to an increase in volume scattering and associated with vegetation rather than open water. In some cases, the incidence angle may have influenced the interpretation of changes in relative brightness. An important case was variations in brightness with incidence angle due to inundated vegetation. A variable threshold for inundated vegetation applied to the individual image strips was found to improve the classification consistency between near and far-range results, and could be used to incrementally improve the multi-temporal image classification.

A variable threshold for inundated vegetation as a function of incidence angle was determined by examining image strips in the near-range/far-range overlap in the ScanSAR imagery acquired just five days apart (see Figure 5). Using this simple empirically derived threshold versus incidence angle, Figure 6 shows a comparison of the inundation classification of two pairs of images acquired five days apart. Figure $6 \mathrm{a}, \mathrm{b}$ shows a comparison of the ScanSAR mid-swath classification with that derived from 
data acquired five days earlier in the near-swath range, and Figure 6c,d shows a comparison of the ScanSAR mid-swath classification to that acquired five days later.

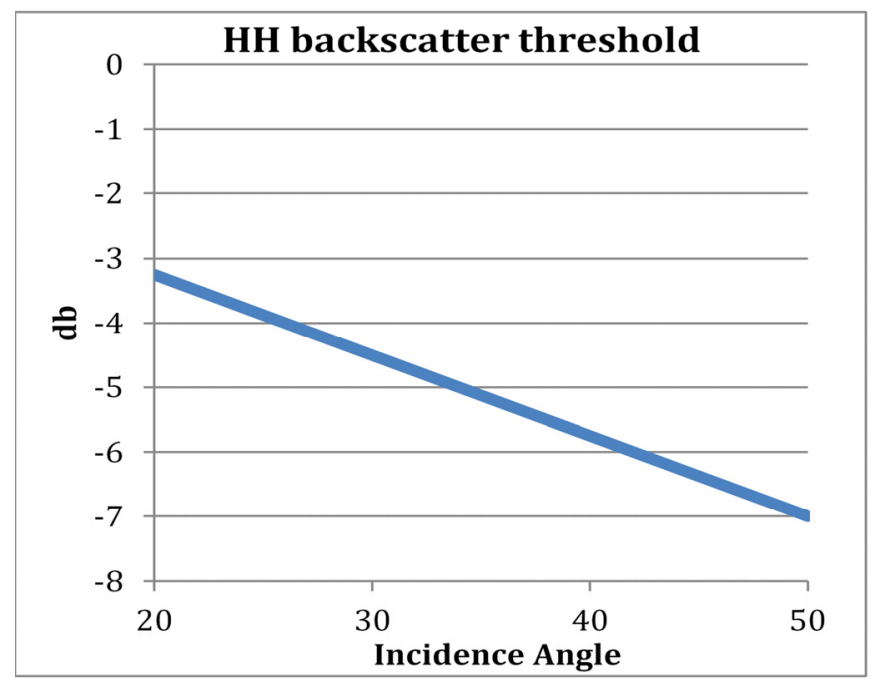

Figure 5. HH backscatter threshold versus incidence angle for the detection of inundation, derived empirically such that similar classifications were obtained in the near and far range of overlapping images acquired five days apart.

a)

$$
\text { b) }
$$

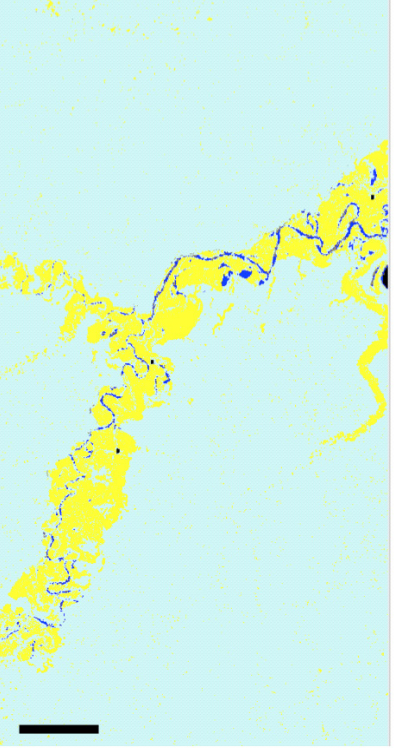

c)

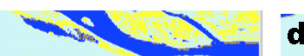

d)
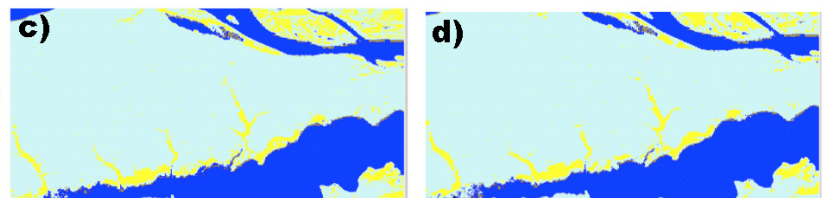
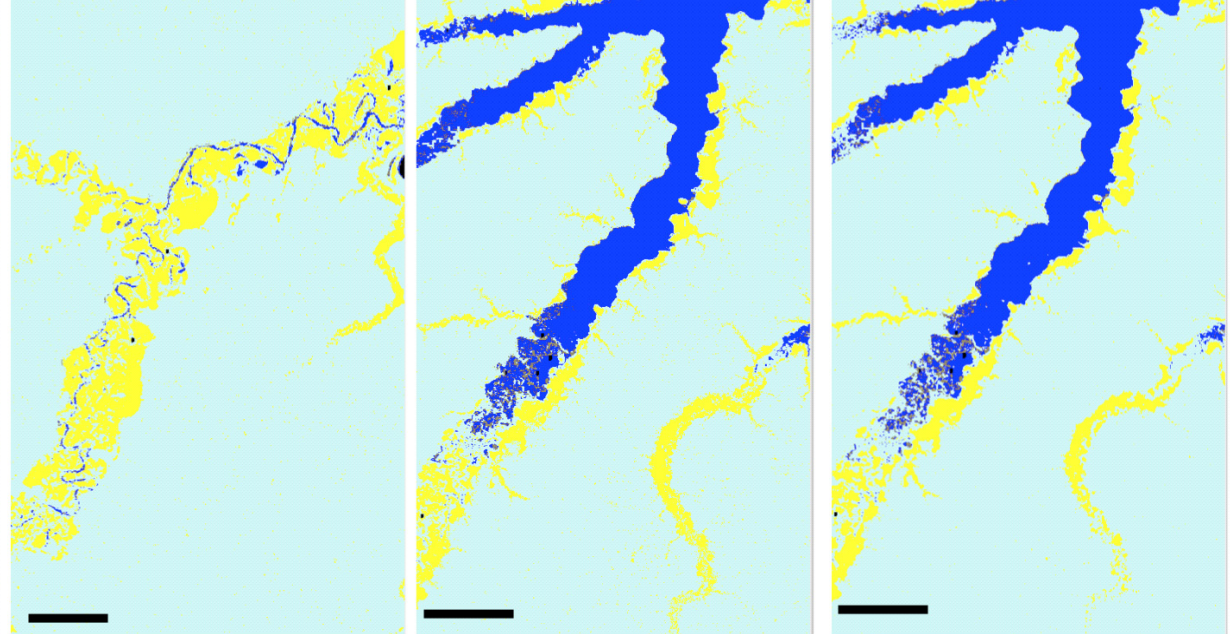

Figure 6. Black bar indicates $10 \mathrm{~km}$ scale. (a) Mid-swath classification from 27 June 2007 (coordinate: $-5.98^{\circ},-64.83^{\circ}$ shown by " $x$ " in Figure 3); (b) near-swath classification from 22 June 2007; (c) mid-swath classification from June 27, 2007 (coordinate $-4.13^{\circ},-63.42^{\circ}$ shown by "y" in Figure 3); (d) far-swath classification from 22 June 2007. Yellow indicates inundated vegetation and dark blue indicates open water. All other areas are unclassified.

We also refined the open water classification based on the SRTM slope; if the class was bare ground or low vegetation, but the slope was zero, the class was changed to "SRTM open water". This association may be made because the only exactly zero-gradient areas in the DEM in bare ground/low vegetation 
areas are those pixels manually edited by the National Geospatial-Intelligence Agency (NGA) to level the elevation of water bodies in version 2.1 of the SRTM DEM [38]. This mainly impacted narrow river areas that were not captured as open water by the ALOS ScanSAR inundation classification. To address ambiguities in radar brightness between open water and some low vegetated and bare ground areas, we used the ESA GlobCover 2009 land cover classification product to establish a secondary category for croplands, as the time sequence of L-band backscatter for harvesting and growth of croplands can mimic those due to inundation events.

The objective for the refinement in the classification described above was to change the initial classification results, when indicated, from a non-inundated class to an inundated class, or from an inundated class to an occasionally inundated class. A maximum and minimum inundation classification may now be derived. Table 2 shows the criteria for the revised classification based on $\Delta_{b}$ for each available date, SRTM slope, and GlobCover class. There were other cases examined, such as inundated vegetation to open water transitions, but these other cases represented a very small percentage of the area classified.

Table 2. Criteria for classification refinement.

\begin{tabular}{ccc}
\hline Initial Class & Condition & Final Class \\
\hline Forest & $\Delta b>3 \mathrm{~dB}$ & Occasionally inundated vegetation \\
Inundated vegetation & $\Delta b<-3 \mathrm{~dB}$ & Occasionally inundated vegetation \\
Inundated vegetation & Variable with incidence angle & Occasionally inundated vegetation \\
Low vegetation & $\Delta b<-3 \mathrm{~dB}$ & Occasionally open water \\
Open water & $\Delta b>6 \mathrm{~dB}$ & Occasionally open water \\
Inundated vegetation & $\Delta b<-12 \mathrm{~dB}$ & Variable inundation state \\
Low vegetation & $\Delta b>10 \mathrm{~dB}$ & Occasionally inundated vegetation \\
Forest & $\Delta b<-10 \mathrm{~dB}$ & Variable inundation state \\
Any except topographic slope & $I_{a}+\Delta b>-5.9 \mathrm{~dB}$ & Occasionally inundated vegetation \\
Any open water or inundated & Maximum SRTM slope $=0$ & SRTM open water vegetation class \\
Any except topographic slope & $11 \leq$ GlobCover2009 class $\leq 201 \mathbf{1}$ & Crops \\
\hline
\end{tabular}

${ }^{1}$ These GlobCover classes correspond to croplands.

Figure 7 shows the resulting maximum and minimum inundation classification for those areas for which we had ALOS ScanSAR multi-temporal image coverage. Given we used a $3 \times 3$ spatial averaging filter to remove speckle noise from the individual ScanSAR image values, we estimate our classification of minimum inundation (Figure $7 \mathrm{~b}$ ) was sensitive to inundation occurring at 1-10 hectare scales.

There are two areas in South America where the ALOS classification results are likely over-estimating the area of open water: south and east of the Amazon River Basin where many agricultural areas were not classified as such by GlobCover; and west of the Andes, where some desert areas, due to their dark radar signature, were classified as open water. 

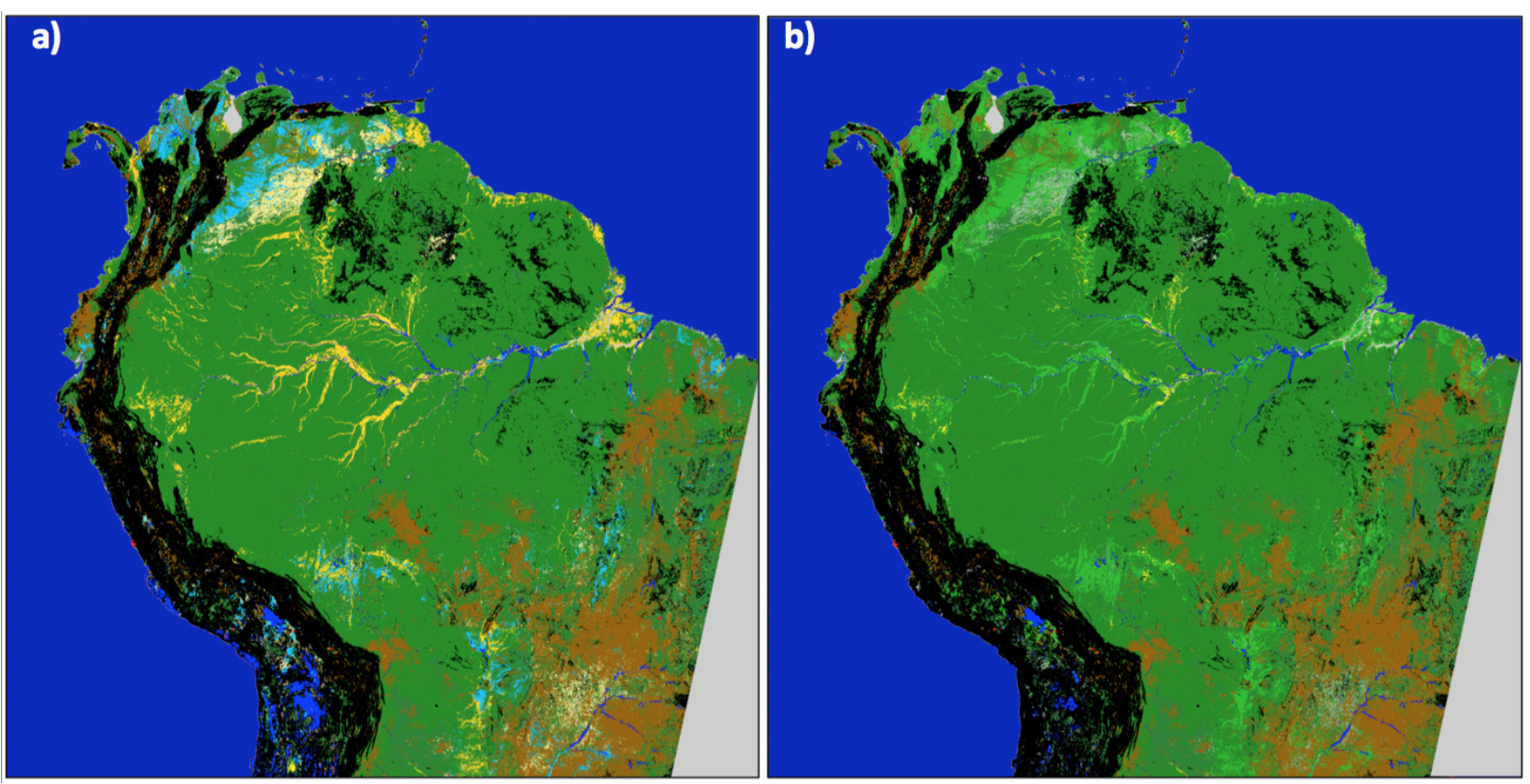

Figure 7. Inundation classification late-2006 to mid-2010; same location as shown in Figure 3. (a) maximum inundation, (b) minimum inundation. Black-topographically excluded; dark blue: open water; light blue: open water maximum; green: not inundated; yellow: inundated vegetation; light yellow: inundated vegetation maximum; brown: croplands from GlobCover 2009; grey: unclassified.

\section{Results and Discussion}

\subsection{Comparison with JERS Results}

During portions of 1995 and 1996, the NASDA JERS-1 L-band SAR regularly imaged the Amazon River Basin [39]. The satellite orbit was well suited to monitoring inundation dynamics, as it progressed westward one image swath per day, as opposed to ALOS PALSAR in ScanSAR mode, in which adjacent swaths are between five and 46 days apart. The disadvantage of the JERS-1 SAR was that the image noise level was higher, which resulted in increased ambiguity when attempting to distinguish open water from low vegetation and bare ground [40].

Individual JERS-1 SAR images were averaged down to approximately 100-meter pixels and mosaicked. A "high" flood mosaic and a "low" flood mosaic were produced. These GRFM mosaics represent average high-water conditions, and lower than average low-water conditions, for the central mainstem floodplain [1]. These image mosaics composed a part of the GRFM project led by NASDA/JAXA and were freely distributed to the scientific community [41]. A "wetland mask" was produced from this imagery, which delineated non-inundated areas from inundated area including both open water and inundated vegetation [4]. Figure 8 shows a comparison of the high flood mosaic, the low flood mosaic, and the wetland mask for the Amazon Basin. The JERS SAR mosaics were created prior to the existence of a high quality DEM for South America; therefore, the mosaics were not radiometrically corrected for terrain slope effects.

While the JERS-1 SAR-derived wetland mask is based on the JERS-1 SAR image mosaics, there is not a direct relation between pixel values of the image mosaics and the wetland mask. The wetland mask was 
constructed though several steps: region-growing segmentation of the image mosaics, unsupervised classification and merging of classes, an editing process to eliminate false positives, manual refinement to include areas adjacent to or surrounded by inundation, and classification of the inundation state. The results for the Central Amazon portion of the mask were carefully validated at strategic locations using airborne videography data [4]. This wetland mask represented the maximum inundatable area, not necessarily the area actually inundated on the dates of the JERS-1 SAR image acquisitions.

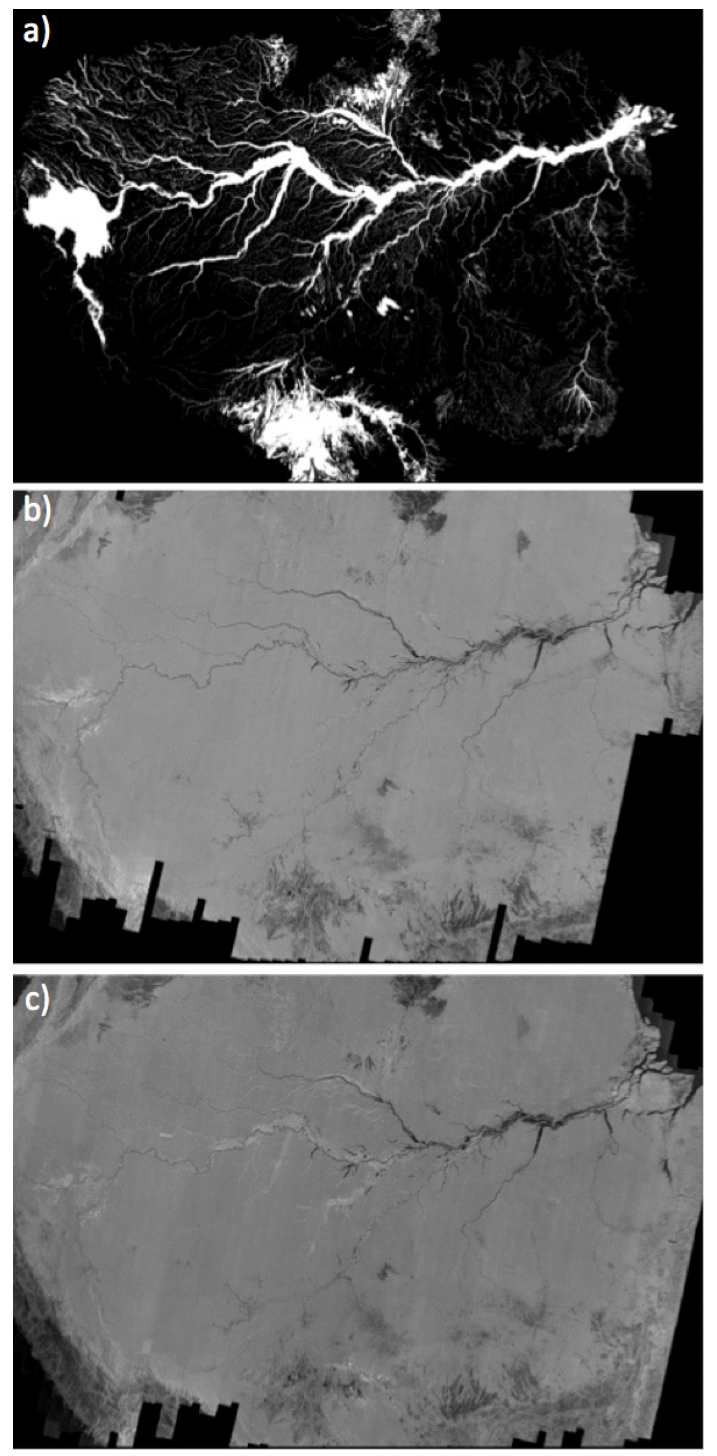

Figure 8. Location shown in Figure 3 by yellow box where horizontal extent is $3500 \mathrm{~km}$. (a) JERS-1 SAR-based wetland mask (white is inundatable; black is not) [4]; (b) JERS-1 SAR image mosaic-Amazon River low flood (late-1995); (c) JERS-1 SAR image mosaic_-Amazon River high flood (mid-1996). CNASDA.

In addition, Melack and Hess (MH; [4]) describe the results of classifying the above JERS imagery into wetlands types within this coverage area. The $\mathrm{MH}$ inundation classes are shown in Table 3. Figure 9 shows the MH classification in comparison with four aggregated inundation classes (maximum open water extent, minimum open water extent, maximum inundated vegetation extent, and minimum inundated vegetation extent) and a class representing steep slopes unlikely to be inundated, extracted from the ALOS classification in Figure 7. We note that there are some geographically distinct differences 
in the inundation classifications; in particular, outside the JERS-1 mask on the eastern coast north and south of the Amazon River, and in the Bolivian wetlands on the southern border of the JERS-1 mask.

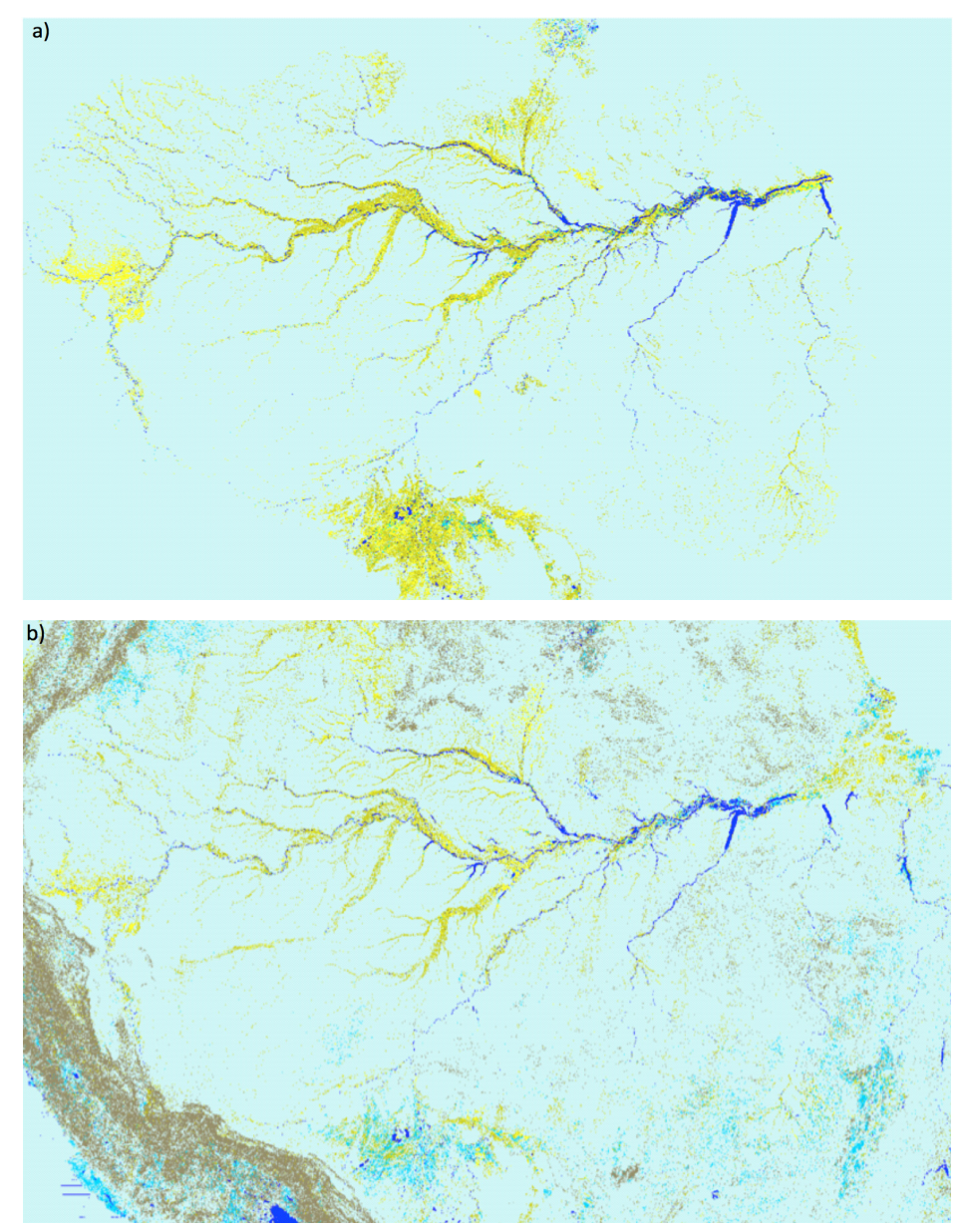

Figure 9. Location shown in Figure 3 by yellow box where horizontal extent is $3500 \mathrm{~km}$. (a) Melack and Hess inundation classification (mid-90s); (b) ALOS inundation classification (2007-2009). Yellow_always inundated vegetation; off-yellow-occasionally inundated vegetation; dark blue — always open water; medium blue — occasionally open water; brown (ALOS only) - high topographic slopes.

Table 3. Inundation categories from Melack and Hess [4].

\begin{tabular}{c}
\hline Inundation Category \\
Open water (one date) \\
Open water (both dates) \\
Flooded herbaceous vegetation (one date) \\
Flooded herbaceous vegetation (both dates) \\
Flooded shrub vegetation (one date) \\
Flooded shrub vegetation (both dates) \\
Flooded woodlands (less than 60\% canopy cover) (both dates) \\
Flooded forest (one date) \\
Flooded forest (both dates)
\end{tabular}

Although standard methods and brightness thresholds have been utilized to generate an inundation classification from the ALOS imagery as shown in Figure 7, it is not possible to do a rigorous validation 
because widespread validation data for inundation extent are not available for the time period of the data acquisition. However, a quantitative comparison between the validated mid-90s JERS-1 based inundation classification by $\mathrm{MH}$ and the classification of the multi-temporal 2007-2009 era data from ALOS may be made. There are three caveats: (1) the JERS-1 classification results and mask sometimes exhibit non-uniformly distributed geolocation differences when compared with the ALOS classification results of $400 \mathrm{~m}$ or more, due to geolocation errors present in the JERS-1 mosaics [42]; (2) inundation patterns captured by the dual season mid-90s JERS-1 based classification may be different than those captured by the 2007-2010 ALOS-based classification; (3) the temporal sampling of both the dual season JERS-1 and the multi-temporal ALOS ScanSAR imagery are insufficient to insure that maximum or minimum inundation extent were present during at least one image acquisition.

Table 4. Comparison of ALOS classification results from Figure 7 and Melack and Hess (MH) classification results (from [4])) for two cases: for those locations where both classifications indicated an inundation class and for those locations where the JERS-1 classification alone indicated an inundation class.

\begin{tabular}{ccc}
\hline Within JERS Mask & $\begin{array}{c}\text { \% of All Pixel Locations Where ALOS and } \\
\text { MH Classifications Both Show Inundation } \\
\text { (Refer to Table 3) }\end{array}$ & $\begin{array}{c}\text { \% of All Pixel Locations Where } \\
\text { MH Classification Shows } \\
\text { Inundation (Refer to Table 3) }\end{array}$ \\
\hline & Maximum Inundation \\
\hline Flooded forest extent & $86 \%$ & $58 \%$ \\
Flooded woodland extent & $7 \%$ & $8 \%$ \\
Flooded herbaceous extent & $2 \%$ & $22 \%$ \\
Flooded shrubs extent & $3 \%$ & $13 \%$ \\
\hline & Minimum Inundation \\
\hline Flooded forest extent & $99 \%$ & $73 \%$ \\
Flooded woodlands extent & $0 \%$ & $13 \%$ \\
Flooded herbaceous extent & $1 \%$ & $15 \%$ \\
\hline
\end{tabular}

We examined the relative sensitivity of the ALOS classification with respect to the four wetland vegetation types of the MH classification (Table 4). First, at both maximum and minimum inundation, we summed the total pixel area where inundated vegetation was indicated in both classifications and calculated the percentage distribution between the $\mathrm{MH}$ inundated vegetation classes. Second, we found the percentage distribution between the MH inundation classes for a subset of the JERS-1 mask. Assuming in the first case that the sampling was random and only limited by either change in the inundation state between the two sets of observations or change in inundation patterns rather than vegetation differences, we found when compared to the entire classification within the JERS-1 mask that the ALOS inundated vegetation class was sensitive to only a small portion of the flooded herbaceous regions (and to a lesser degree, flooded shrubs). In the case of flooded herbaceous vegetation, Figure 10 illustrates an example where these areas were classified by the ALOS classification as occasionally open water, as the L-band backscatter signature in these areas was dominated by the open water surface scatter rather than the herbaceous vegetation. In the case of flooded shrubs, Figure 11 shows an example where these areas were classified as not inundated, as the L-band backscatter signatures for these flooded environments were not easily discernable from other non-flooded environments. Given the lack of sensitivity to these vegetation types, 
we found that the best correspondence of the ALOS inundated vegetation class was with the MH flooded forest class and flooded woodland class; however, the MH flooded woodlands class was not observed within the ALOS inundated vegetation class at minimum inundation.

a)

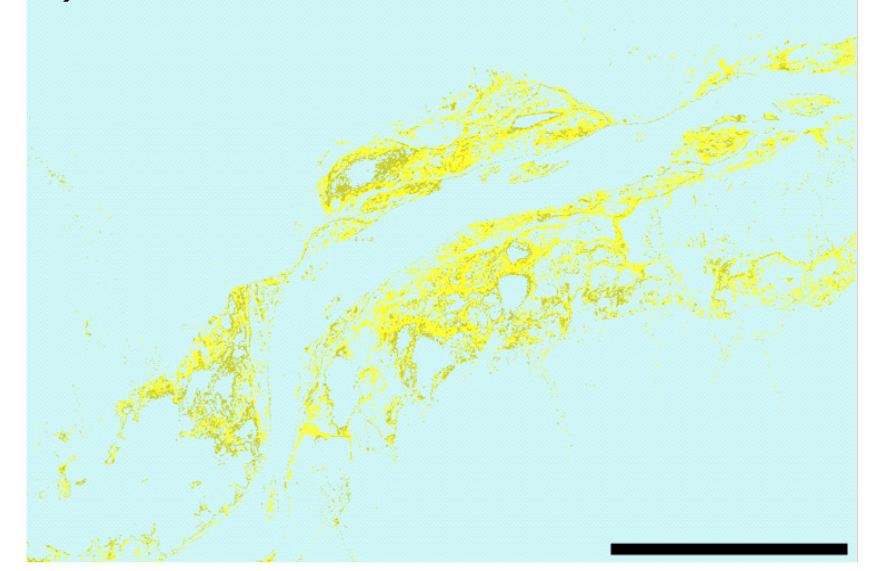

b)

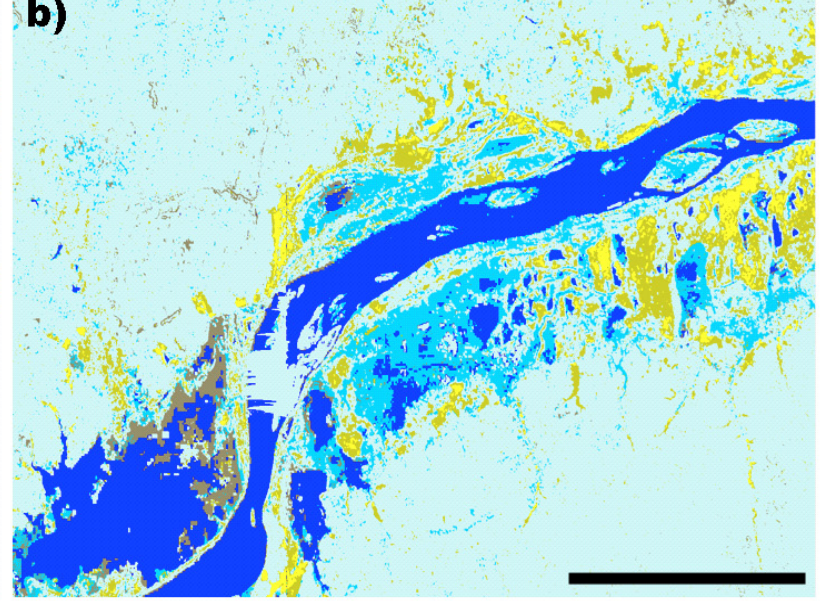

Figure 10. (a) Melack and Hess classification, where yellow and off-yellow indicate maximum extent of flooded herbaceous vegetation; (b) ALOS classification, where dark blue and medium blue indicate maximum extent of open water and yellow and off-yellow indicate always or occasionally flooded vegetation, respectively. The flooded herbaceous classes tend to be classified as open water (and sometimes as not inundated) in the ALOS classification. (center coordinates: $-1.978^{\circ},-53.708^{\circ}$, shown by letter "w" in Figure 3. The black bar indicates $50 \mathrm{~km}$ scale).

a)

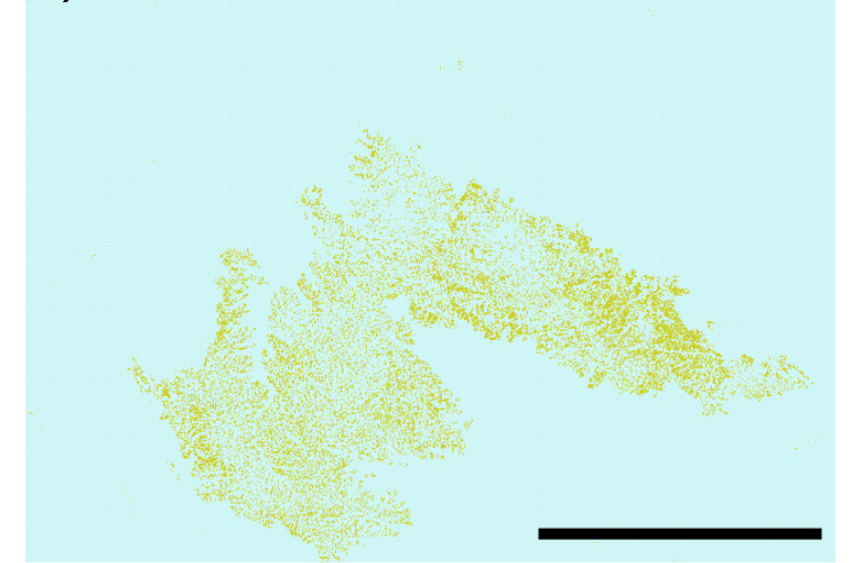

b)

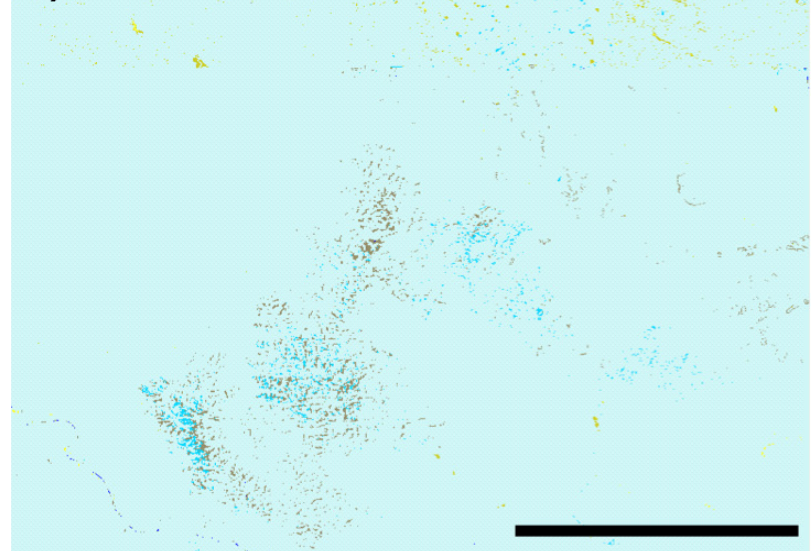

Figure 11. (a) Melack and Hess classification, where off-yellow indicate maximum extent of flooded shrubs; (b) ALOS classification, where dark blue and medium blue indicate maximum extent of open water and brown represents areas of steep slope not likely to be inundated. The flooded shrub classes tend to be classified as not inundated in the ALOS classification. (center coordinates: $-8.487^{\circ},-61.788^{\circ}$ shown by letter " $z$ " in Figure 3 , black bar indicates $50 \mathrm{~km}$ scale).

Table 5 indicates the total area of inundated vegetation and open water at maximum and minimum inundation within the JERS-1 mask for both the MH classification and the ALOS classification shown 
in Figure 7. The most striking difference was the area of inundated vegetation at minimum inundation. The ALOS classification indicated a much smaller minimum inundated vegetation area, possibly due to the improved temporal sampling of the ALOS ScanSAR imagery during minimum inundation. It is also possible the larger number of looks present in the JERS-1 SAR imagery provide a more robust assessment. The area of inundated vegetation as shown in Figure 7 from ALOS at maximum inundation was less than that indicated by the MH classification. The ALOS classification had a much larger increase in open water at maximum inundation, predominantly due to the large wetland area in Bolivia, classified in the ALOS classification as mostly open water at maximum inundation, but as flooded herbaceous and flooded woodlands in the MH classification.

Table 5. Maximum and minimum area of inundation within the JERS-1 mask from both the Melack and Hess classification and the ALOS classification shown in Figure 7.

\begin{tabular}{ccccccc}
\hline $\begin{array}{c}\text { Within } \\
\text { JERS Mask }\end{array}$ & $\begin{array}{c}\text { ALOS Inundated } \\
\text { Vegetation (Mha) }\end{array}$ & $\begin{array}{c}\text { MH Flooded } \\
\text { Forest (Mha) }\end{array}$ & $\begin{array}{c}\text { MH, Flooded } \\
\text { Woodland (Mha) }\end{array}$ & $\begin{array}{c}\text { ALOS Open } \\
\text { Water (Mha) }\end{array}$ & $\begin{array}{c}\text { MH, Open } \\
\text { Water (Mha) }\end{array}$ & $\begin{array}{c}\text { MH, Flooded } \\
\text { Herbaceous (Mha) }\end{array}$ \\
\hline $\begin{array}{c}\text { Maximum } \\
\text { inundation } \\
\begin{array}{l}\text { Minimum } \\
\text { inundation }\end{array}\end{array}$ & 20.7 & 23.8 & 5.2 & 8.8 & 8.4 & 9.3 \\
\hline
\end{tabular}

\subsection{Monitoring Inundation Dynamics}

To examine inundation dynamics, we needed to analyze individual ScanSAR imagery from specific dates. As the ALOS ScanSAR path images had only three looks, the inundation state classification of individual image strips could be much noisier in quality than that developed using all of the ScanSAR imagery. Therefore, our approach was to incrementally add to inundation extent from the minimum ALOS ScanSAR estimated inundation state if $\Delta b$ within occasionally inundated areas clearly indicated an identifiable change in inundation state. Table 6 tabulates the conditions that determine the estimated inundation state for each ScanSAR path image.

Table 6. Criteria for assessing inundation state for each ALOS ScanSAR acquisition.

\begin{tabular}{ccc}
\hline ALOS Maximum Inundation Class & Criteria & Temporal Class \\
\hline Occasionally inundated vegetation or forest & $\Delta b>3 \mathrm{~dB}$ & Inundated vegetation \\
Occasionally inundated vegetation or forest & $\Delta b<-10 \mathrm{~dB}$ and $\theta_{x, y}>29^{\circ}$ & Open water \\
Low vegetation, forest, or occasionally open water & $\Delta b<-3 \mathrm{~dB}$ and $\theta_{x, y}>29^{\circ}$ & Open water \\
Low vegetation or occasionally open water & $\Delta b<10 \mathrm{~dB}$ & Inundated vegetation \\
Low vegetation or occasionally open water & $\Delta b>10 \mathrm{~dB}$ & Inundated vegetation \\
Always inundated vegetation & & Open water \\
Always inundated vegetation & & Inundated vegetation \\
\hline
\end{tabular}

These $\Delta b$ values were chosen to increase the likelihood that inundation (or lack thereof) would be detected as well as be robust in the presence of calibration errors or more subtle environmental changes separate from inundation. However, there are other environmental changes that result in changes in backscatter of this magnitude, such as deforestation or growth and harvesting of crops. This is why crop areas were masked out using ESA's GLOBCOVER land cover classification product (see Table 1). 
There is evidence, however, that GLOBCOVER underestimates crop area, which together with its coarser scale, could affect the accuracy of this classification in cropland areas [43].

To assess the fidelity of these single date inundation products, the inundation dynamics of the large swamp forests in the western Amazon lowlands were examined. The inundated vegetation in this region is categorized, in order of degree of water logging, as herbaceous marshes, shrub swamps, palm swamps, and forest swamps [44]. Shrub swamps often surround the herbaceous marshes. Palm swamps are found throughout the region, inundated by rains or ground water, or less frequently near rivers. Forest swamps are often transitional zones around other types of swamps and also are found along small streams and interfluvial sites with poor drainage. Forest patches with dead or dying trees are not uncommon and often are surrounded by open water. Some areas are characterized by a mosaic of herbaceous and forested swamps occurring in depressions, with forests on the ridges [44]. We expect the shrub swamps and herbaceous marshes to be difficult to detect. Each of these wetland types will vary slightly in the ALOS ScanSAR HH radar backscatter signature, where the herbaceous marshes will have the most ambiguity of detection.

Table 7 shows the inundation classes within the MH inundatable mask of $100,000 \mathrm{~km}^{2}$ surrounding the Pacaya-Samiria Reserve, shown in Figure 12a. Our results are similar to the $24,900 \mathrm{~km}^{2}$ of swamp vegetation estimated by Kalliola et al. [44] in this area using Landsat TM, in situ data, aerial surveys and side-looking airborne radar data. We found that open water at minimum inundation decreased by $28 \%$ from maximum inundation, but flooded vegetation decreased by a substantially larger fraction, $73 \%$.

Table 7. Results from within the inundatable mask for Pacaya-Samiria, Peru and surrounding areas.

\begin{tabular}{cc}
\hline & Area from ALOS ScanSAR Classification $\mathbf{( k m}^{\mathbf{2}} \mathbf{~}$ \\
\hline & Maximum \\
\hline Open water & 1504 \\
Flooded vegetation & 26,074 \\
Combined & 27,578 \\
\hline & Minimum \\
\hline Open water & 1085 \\
Flooded vegetation & 6939 \\
Combined & 8024 \\
\hline Melack and Hess [4] mask inundatable area: $103,673 \mathrm{~km}^{2}$
\end{tabular}

We also examined the fractional area of inundation for a large site $\left(2000 \mathrm{~km}^{2}\right)$ within the Pacaya-Samiria Reserve for six dates in 2007 (Figure 12b). The inundation duration was broad for this area, with maximum inundation occurring late April or early May 2007. The dry season occurred roughly between June and September, where its lowest water levels were $10 \mathrm{~m}$ or more below those of the peak water levels. The inundation fraction within the indicated box in Figure 12 ranged from 0.6 (late April) to 0.1 (end of September) during this time period. Figure 13 shows the progression of inundation for this for the six observation dates.

We examined relative inundation duration from the results shown in Figure 13, along with classification results from a seventh SCANSAR image from 3 August 2008, all obtained from orbit path 445 . We categorized each image pixel according to how many times inundated vegetation was identified during the seven observation dates. (Figure 14, Table 8). Areas that were inundated in every acquisition accounted 
for over $25 \%$ of the inundated area, whereas over $30 \%$ of the inundated area was inundated in only a single acquisition. Examining the pattern of inundation, we found that areas to the north of the Marañon River and south of the Ucayali River were more likely to be permanently inundated than those areas between the two rivers.

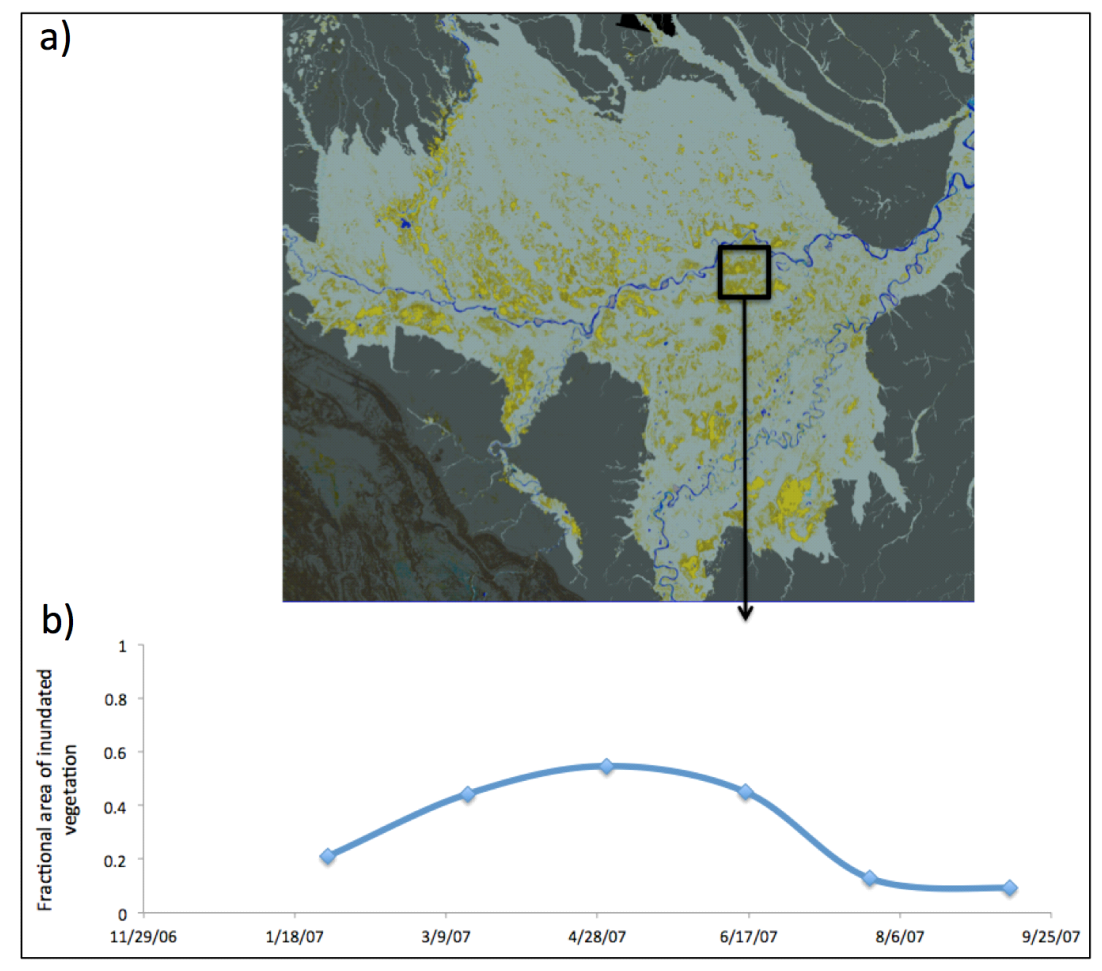

Figure 12. (a) Inundation classification for Pacaya_Samiria, Peru, and surrounding locations, overlaid on JERS-1 based wetland mask, centered on letter "c" in Figure 3. The black box is $45 \mathrm{~km}$ by $45 \mathrm{~km}$. The colors of the inundation classification are overlaid on the JERS-1 based wetland mask, (light grey indicates inundatable and dark grey indicates outside the inundatable area; (b) ALOS ScanSAR estimated inundation dynamics for box shown in (a) depicting fractional total inundation versus time. yellow: always inundated vegetation; off-yellow: occasionally inundated vegetation; dark blue: always open water; medium blue: occasionally open water; brown (ALOS only): high topographic slopes.
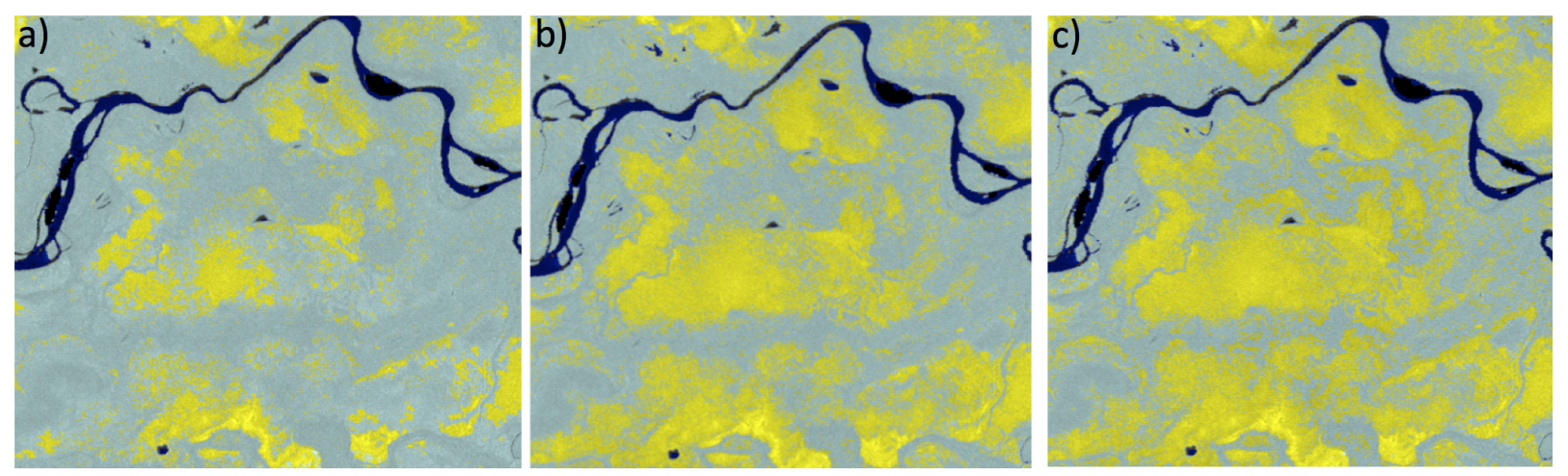

Figure 13. Cont. 


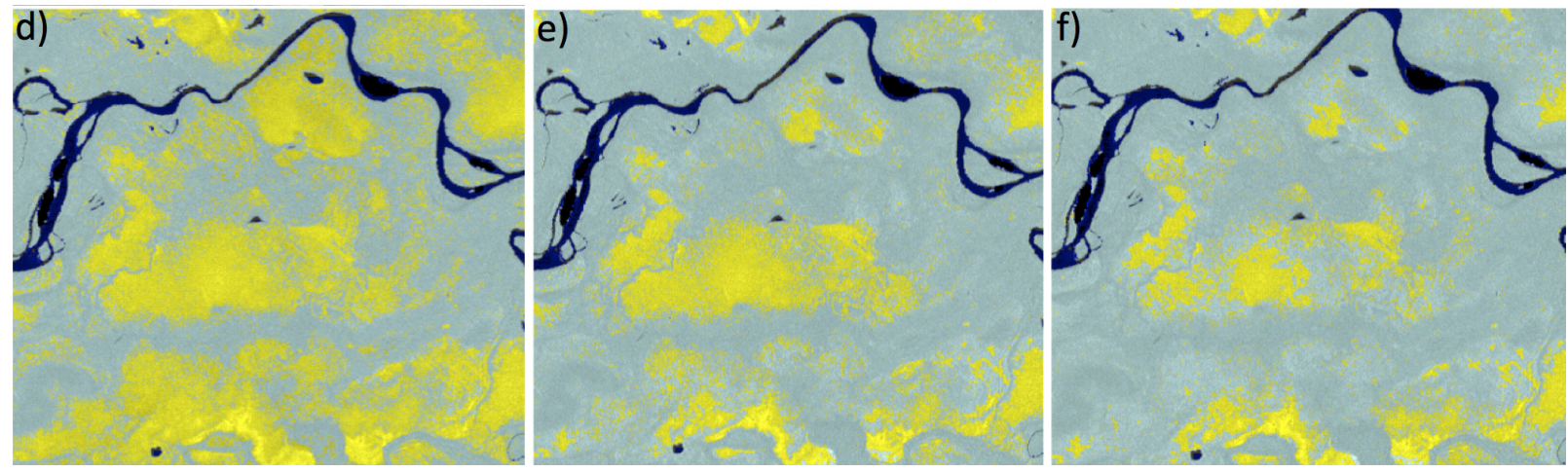

Figure 13. Classification overlaid on low contrast multi-temporal image mosaic of the area within the box from Figure 12 for specific ScanSAR observations acquired from the same path orbit, at letter "c" in Figure 3. Area shown is $45 \mathrm{~km}$ by $45 \mathrm{~km}$. (a) 29 January 2007; (b) 16 March 2007; (c) 1 May 2007; (d) 16 June 2007; (e) 1 August 2007; (f) 16 September 2007. Yellow is inundated vegetation on the date of observation; black is open water. Area shown is $2000 \mathrm{~km}^{2}$.

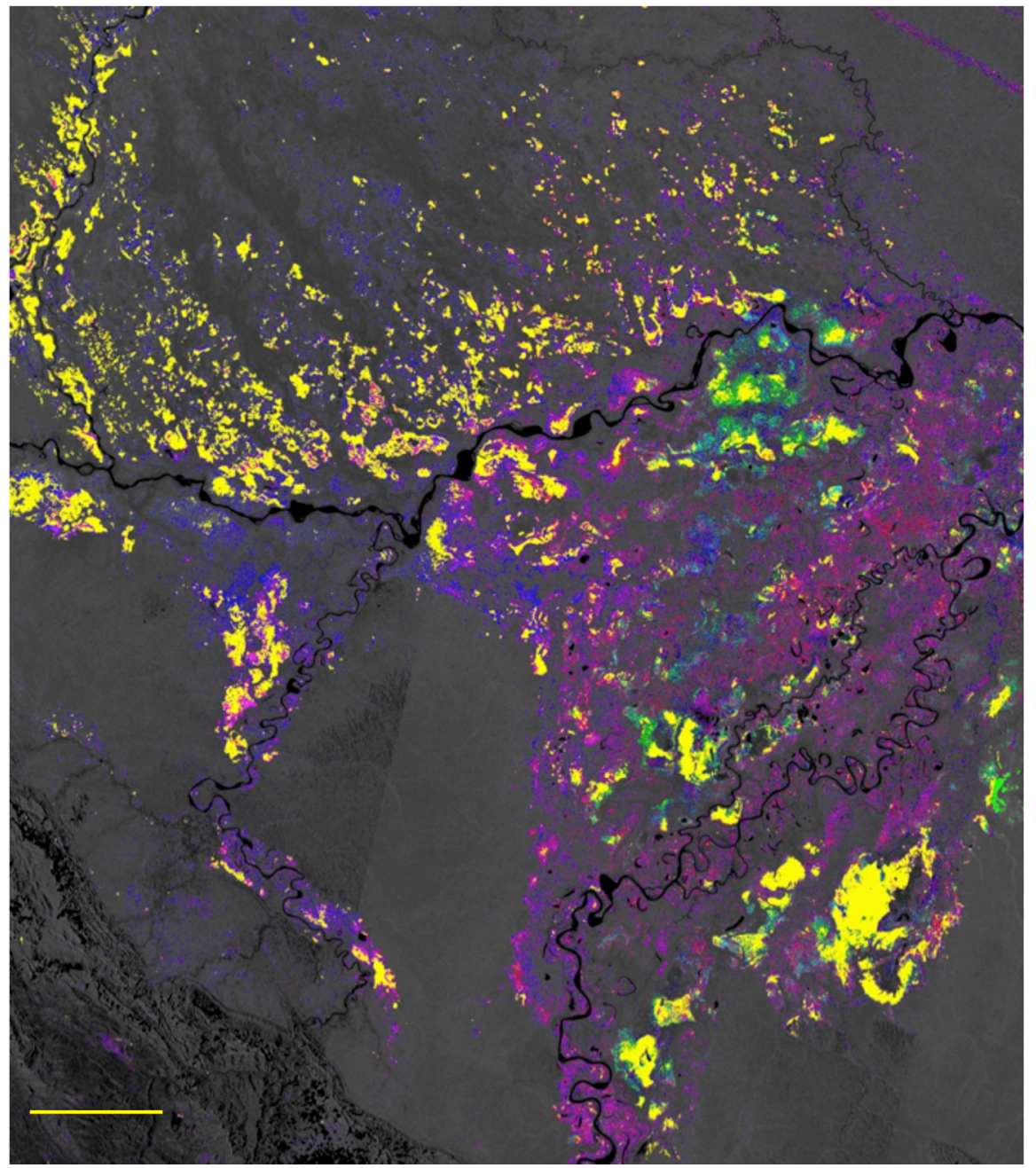

Yellow: inundated in all seven observations; light green: inundated in six observations; dark green: inundated in five observations; turquoise: inundated in four observations; red: inundated in three observations; pink: inundated in two observations; dark blue: inundated in one observation; dark grey: inundation not observed

Figure 14. Inundation duration (for vegetated areas) estimated from seven images acquired between 2007 and 2008 from a single orbit path for the Pacaya-Samiria Reserve (area "c" in Figure 3) and surrounding areas in Peruvian Amazon. The area shown spans $300 \mathrm{~km}$ from east to west and $350 \mathrm{~km}$ from north to south. The yellow bar shows $50 \mathrm{~km}$ scale. Background is low contrast multi-temporal image mosaic. 
Table 8. Area of each category of relative inundation duration (i.e., number of dates inundated). Colors correspond with those shown in Figure 14.

\begin{tabular}{cc}
\hline Relative Inundation Duration & Area \\
\hline 7 (Yellow) & $6939 \mathrm{~km}^{2}$ \\
6 (Light Green) & $540 \mathrm{~km}^{2}$ \\
5 (Dark Green) & $911 \mathrm{~km}^{2}$ \\
4 (Turquoise) & $1715 \mathrm{~km}^{2}$ \\
3 (Red) & $2952 \mathrm{~km}^{2}$ \\
2 (Pink) & $4778 \mathrm{~km}^{2}$ \\
1 (Dark Blue) & $8237 \mathrm{~km}^{2}$ \\
\hline
\end{tabular}

\subsection{Comparison with Coarse Resolution Surface Water Fraction Estimates}

Finally, we compared wetland classifications generated from high resolution ALOS PALSAR data with that generated from much lower resolution (but much shorter orbit repeat intervals of three days or less) spaceborne sensors such as AMSR-E, which is a passive microwave radiometer. The coarse resolution surface water fraction product from these sensors was generated globally and aggregated to 10-day intervals. Each $25 \times 25 \mathrm{~km}$ grid cell represented fractional surface water area. The AMSR-E inundation product used herein was that of Schroeder et al. [45], extended to all snow-free days from July 2002 through July 2009 [46].

To facilitate this comparison, we generated a $25 \mathrm{~km}$ pixel-spacing fractional open water map and a $25 \mathrm{~km}$ pixel-spacing fractional inundated vegetation map from our maximum and minimum inundation classifications derived from ALOS ScanSAR data (refer to Figure 7). Likewise, we examined the 10-day coarse resolution surface water fraction product for the time span roughly corresponding to the ALOS acquisitions (November 2006 to July 2009) and produced a maximum and minimum surface water fraction product. As can be seen from Figure 15, the coarse resolution surface water fraction most closely agreed with the fraction of open water estimated from ALOS ScanSAR, rather than the fraction of inundated vegetation, perhaps because the coarse resolution sensors are less sensitive to water beneath a vegetation canopy. We found qualitative agreement between the coarse resolution surface water fraction and the ALOS derived open-water fraction at both maximum and minimum inundation.

In general, we found that the maximum coarse resolution surface water fraction was slightly less than or similar to the ALOS maximum open water fraction, except in the northwestern and southeastern quadrants of the mapped area and along major rivers, where the maximum ALOS open water fraction was substantially greater. These open water areas are regions where seasonal flooding can occur and are either being overestimated by the ALOS ScanSAR classification or underestimated by the coarse resolution surface water fraction product. Since it is likely water depth is quite shallow in these areas, it could be a matter of the definition of what constitutes "open water;" the ScanSAR data are sensitive to shallow but widespread flooding, but the coarse resolution product requires a noticeable change in measured emissivity by AMSR-E. It also may be that bare soil or low vegetation associated with agriculture or ranching in these areas has backscatter values as low as open water. The ALOS ScanSAR classification results over agricultural areas and ranchlands present in some of these areas, and not masked by ESA's GlobCover land cover classification product, may account for part of the discrepancy, as well as desert areas to the west of the Andes where the dark radar returns are similar to those for open water. 

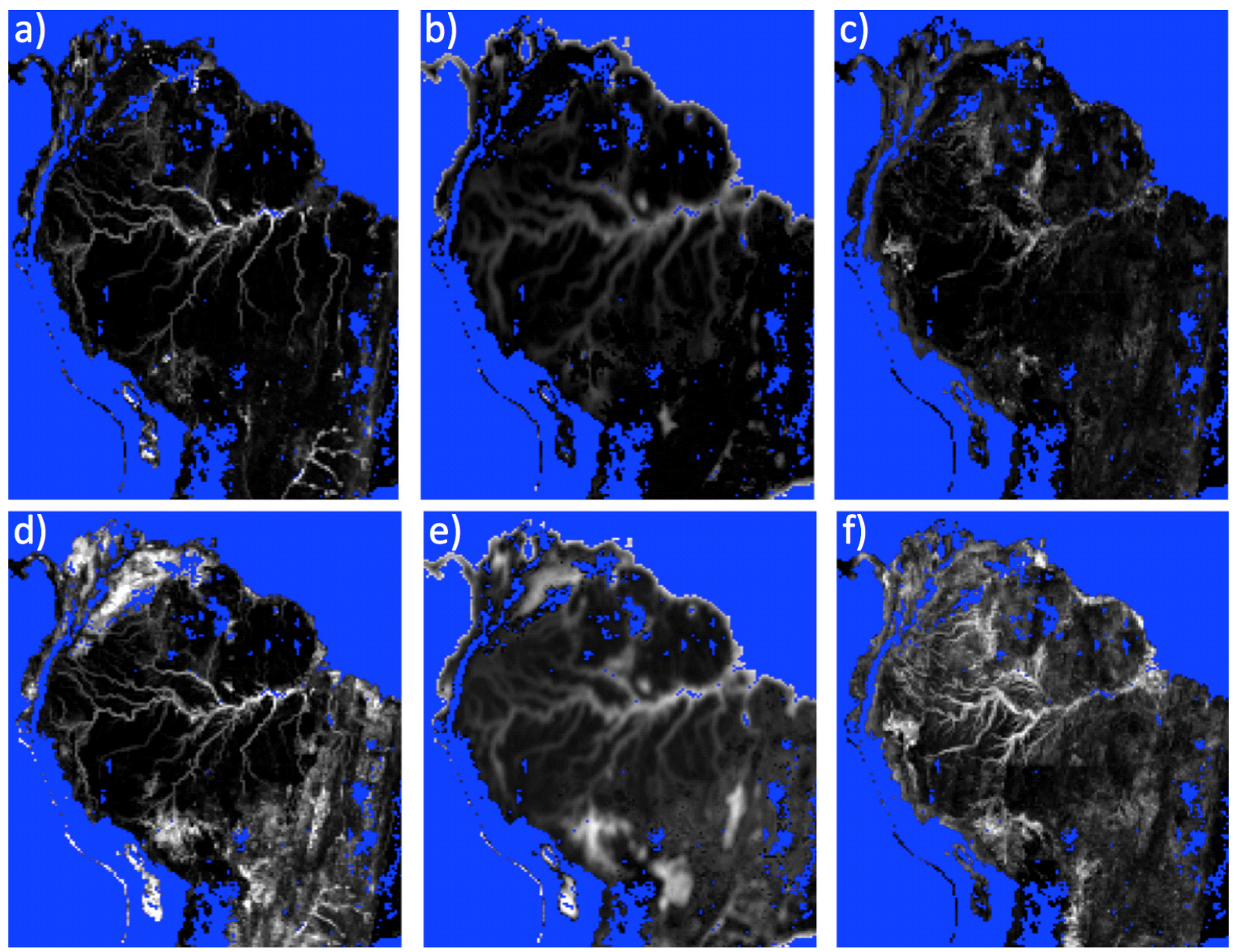

Figure 15. Comparison of inundation and coarse-resolution surface water fraction products for the same area shown in Figure 3. (a) Minimum fraction of open water from ALOS ScanSAR classification; (b) minimum fractional surface water area from coarse resolution sensors; (c) minimum fraction of inundated vegetation from ALOS ScanSAR classification; (d) maximum fraction of open water from ALOS ScanSAR classification; (e) maximum fractional surface water area from coarse resolution sensors; (f) maximum fraction of inundated vegetation from ALOS ScanSAR classification. Blue indicates masked pixels; grey scale indicates relative fractional inundation with white indicating maximum surface water fraction and black indicating no inundation.

We examined the relationship of these coarse resolution surface water fraction data sets to each other quantitatively. Figure 16 shows, within the JERS-1 image mosaic region area, plots of the maximum ALOS open water fraction, the maximum ALOS inundated vegetation fraction, and the JERS-1 based wetland fractional mask versus the maximum coarse resolution surface water fraction, aggregated for every $1^{\circ}$ by $1^{\circ}$ in latitude and longitude. We found that, in general, there was close to a one-to-one relation between ALOS open water fraction and the coarse resolution surface water fraction (slope $=0.89$ ), but the maximum inundated vegetation fraction and JERS-1 based wetland mask showed a significant divergence from a one-to-one slope. Note that by choosing the JERS-1 image mosaic area, we excluded the areas where the values diverge. This not only demonstrates the correspondence of SAR classification of open water extent to coarse resolution inundation fraction products such as that derived by AMSR-E, but also the need for L-band products for monitoring inundation beneath forest canopies. 
(a)

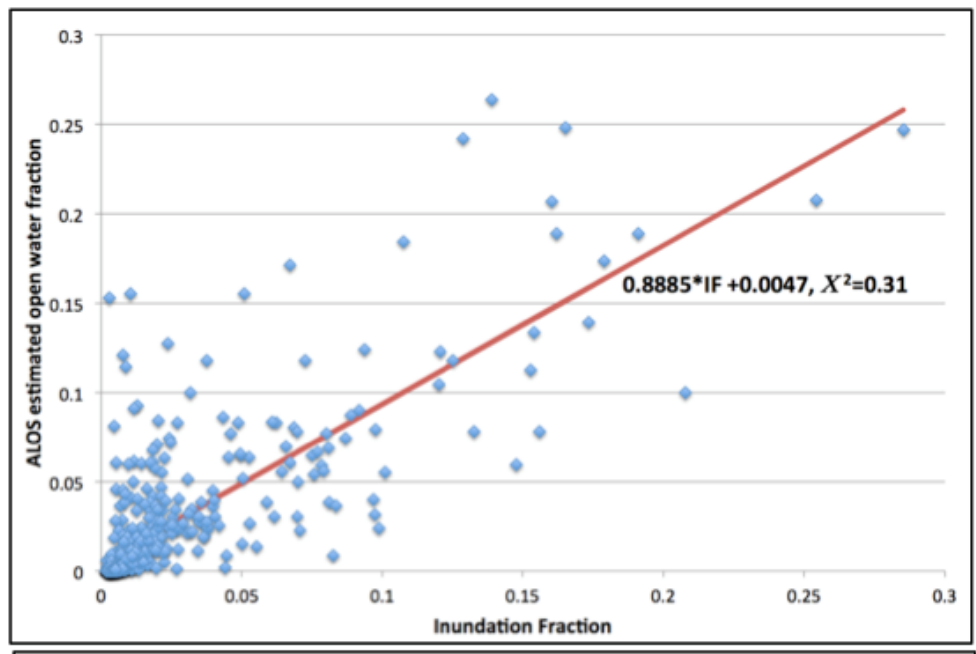

(b)

(c)
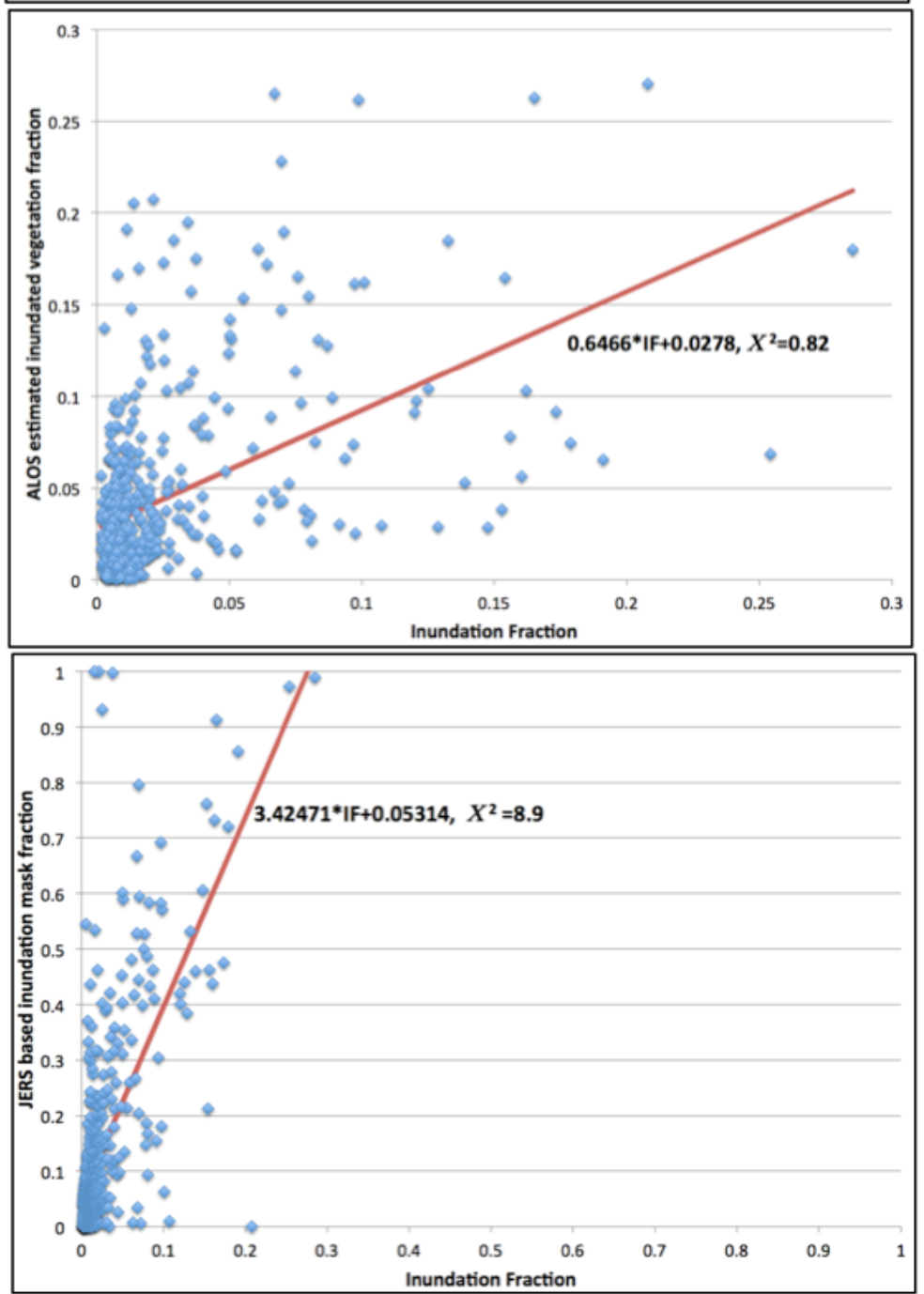

Figure 16. Comparison of ALOS and JERS-1 products with coarse-resolution surface water fraction. (a) ALOS open water fraction; (b) ALOS inundated vegetation fraction; (c) JERS-1-based mask (where there is overlap) versus the coarse resolution surface water fraction. Note that the scale of (c) is much larger. Only the ALOS open water fraction has a significant relation to the coarse resolution surface water fraction estimates. 


\section{Conclusions}

The objectives of this work were to assemble and mosaic JAXA L-band ALOS PALSAR ScanSAR imagery for analysis of wetland dynamics at continental scales, then use existing algorithms for identifying inundation, both open water extent and inundated vegetation extent. The ALOS PALSAR ScanSAR data obtained through JAXA's ALOS Kyoto and Carbon Initiative, in coordination with a NASA MEASURES task to produce an Earth Science Data Record (ESDR), have been used to classify inundation state for all of South America north of $24^{\circ} \mathrm{S}$ latitude.

With properly orthorectified and calibrated data, we found, as expected, that the radar signatures for inundated vegetation and open water were easily identified. Classification parameters were assigned from published criteria derived from extensive field measurements, together with a multi-temporal analysis of backscatter change.

We compared the ALOS ScanSAR classification results at maximum and minimum inundation state with a JERS-1 based wetland classification. We also compared results against a JERS-1 based wetland mask that identified inundatable area. Our results showed that the ALOS ScanSAR classification of inundated vegetation was relatively insensitive to inundated herbaceous vegetation. Polarimetric L-band SAR observations, or additional observations at a shorter wavelength, may improve the capability of future spaceborne SAR missions to detect these marshes.

The existence of an inundatable mask significantly improved the likelihood of a correct classification, as it eliminated areas unlikely to be inundated; some of the areas eliminated may have radar signatures similar to those from inundation events. An inland inundatable mask, based on data sources such as SRTM (for examining slope) and products like GlobCover, could be constructed to include all known inland floodplains, rivers, and lakes, but exclude urban areas, most desert areas, most agricultural areas, volcanic lava flows, ocean boundaries, and areas of large slopes. Using such a mask, even if it overrepresented the inundatable area, would significantly improve the classification accuracy by excluding those areas that are unlikely to be inundated.

Inundation dynamics were examined using the multi-temporal ALOS ScanSAR acquisitions over the Pacaya-Samiria and surrounding areas in the Western Amazon lowlands of Peru. Relative inundation duration was estimated, revealing distinct local variations likely associated with differing swamp characteristics.

Lastly, we compared inundation results from the ALOS multi-temporal ScanSAR classification with independent results from the coarse resolution sensor AMSR-E, acquired during the same time period. Good correspondence was found when comparing open water extent with surface water fraction, except in regions where there may be differences in sensitivity to widespread and shallow seasonal flooding events, or in areas that would be masked out from analysis if a continental scale inundatable mask was available, one conceptually similar to the JERS-1 based wetland mask for the lowland Amazon.

These results compose a portion of an Inundated Wetlands Earth Science Data Record (IW-ESDR) funded by NASA's MEaSUREs program. Through this program, these data products are made available through the ASF wetlands portal at the Alaska Satellite Facility Data Active Archive Center (ASF DAAC) [47].

Further study is required to fully understand the uncertainties in these results; in particular, polarimetric and interferometric L-band SAR data such as will be collected on a wide scale by the JAXA ALOS-2 
L-band SAR mission and the forthcoming NASA/ISRO L-band SAR mission, will be capable of enhanced monitoring of large-scale wetland dynamics. Validation using $\mathrm{HH}$ and $\mathrm{HV}$ over a broad range of incidence angles and incorporating zero-baseline interferometric results to identify inundation state have not yet been conducted over globally representative regions.

\section{Acknowledgments}

We thank the NASA MEaSUREs program and Martha Maiden for funding this work, the NASDA/JAXA GRFM project for the JERS-1 imagery, the Alaska Satellite Facility ALOS Data node for ancillary ALOS data, the global classification from ESA's GlobClover land cover classification product, and the NASA SRTM project for its near global DEM. This research was undertaken within the framework of the ALOS Kyoto \& Carbon Initiative. The ALOS data were provided by JAXA EORC. Resources supporting this work were provided by the NASA High-End Computing (HEC) Program through the NASA Advanced Supercomputing (NAS) Division at Ames Research Center. We also thank the editor and the reviewers for their advice and suggestions for the improvement of this paper.

This work was partially performed at the Jet Propulsion Laboratory, California Institute of Technology, under contract with the National Aeronautics and Space Administration. U.S. Government sponsorship acknowledged.

\section{Author Contributions}

B.C. wrote the paper, created the figures, produced the SAR image products and inundation products, and analyzed statistics for the products and product comparisons. K.M. led the development of the concept for the inundated wetlands earth science data record, was actively involved in acquisition planning for the SAR data, and oversaw the development of the inundation fraction product. R.S. developed the inundation fraction and assisted in the interpretation of this data relative to this work. A.R. developed the observation scenario for the data acquisition and the conception of the wetlands theme for the ALOS Kyoto and Carbon Initiative. M.S. developed the path image products that were used to produce the image products used here. He was also actively involved in the acquisition strategy to obtain the data. L.H. contributed to the development of the concept for the inundated wetlands earth science data record, was actively involved in acquisition planning for the SAR data, and contributed validation maps and their interpretation relative to this work.

\section{Conflicts of Interest}

The authors declare no conflict of interest.

\section{References}

1. Hess, L.L.; Melack, J.M.; Novo, E.M.L.M.; Barbosa, C.C.F.; Gastil, M. Dual-season mapping of wetland inundation and vegetation for the central Amazon region. Remote Sens. Environ. 2003, $87,404-428$. 
2. Hess, L.L.; Melack, J.M.; Filoso, S.; Wang, Y. Delineation of inundated area and vegetation along the Amazon floodplain with the SIR-C synthetic aperture radar. IEEE Trans. Geosci. Remote Sens. 1995, 33, 896-904.

3. Richey, J.E.; Melack, J.M.; Aufdenkampe, A.K.; Ballester, V.M.; Hess, L.L. Outgassing from Amazonian rivers and wetlands as a large tropical source of atmospheric $\mathrm{CO}_{2}$. Nature 2002, 416, 617-620.

4. Melack, J.M.; Hess, L.L. Remote sensing of the distribution and extent of wetlands in the Amazon basin. In Amazonian Floodplain Forests: Ecophysiology, Ecology, Biodiversity and Sustainable Management; Junk, W.J., Piedade, M., Wittmann, F., Schöngart, J., Parolin, P., Eds.; Springer: New York, NY, USA, 2011; pp. 43-59.

5. Melton, J.R.; Wania, R.; Hodson, E.L.; Poulter, B.; Ringeval, B.; Spahni, R.; Bohn, T.; Avis, C.A.; Beerling, D.J.; Chen, G.; et al. Present state of global wetland extent and wetland methane modeling: conclusions from a model inter-comparison project. Biogeosciences 2013, 10, 753-788.

6. Cox, P.M.; Betts1, R.A.; Collins, M.; Harris, P.P.; Huntingford, C.; Jon, C.D. Amazonian forest dieback under climate-carbon cycle projections for the 21st century. Theor. Appl. Climatol. 2004, $78,137-156$.

7. Huntingford, C.; Fisher, R.A.; Mercado, L.; Booth, B.; Sitch, S.; Harris, P.P.; Cox, P.M.; Jones, C.D.; Betts, R.A.; Malhi, Y.; et al. Towards quantifying uncertainty in predictions of Amazon “dieback”. Phil. Trans. R. Soc. B 2008, doi:10.1098/rstb.2007.0028.

8. Lenton, T.M.; Held, H.; Kriegler, E.; Hall, J.W.; Lucht, W.; Rahmstorf, S.; Schellnhuber, H.J. Tipping elements in the Earth's climate system. Proc. Natl. Acad. Sci. USA 2008, 105, 1786-1793.

9. Smith, L.C. Satellite remote sensing of river inundation area, stage, and discharge: A review. Hydrol. Process. 1997, 11, 1427-1439.

10. Vanderbilt, V.C.; Perry, G.L.; Livingston, G.P.; Ustin, S.L.; Barrios, M.C.D.; Bréon, F.-M.; Leroy, M.M.; Balois, J.-Y.; Morrissey, L.A.; Shewchuk, S.R.; et al. Inundation discriminated using sun glint. IEEE Trans. Geosci. Remote Sens. 2002, 40, 1279-1287.

11. Prigent, C.; Papa, F.; Aires, F.; Rossow, W.B.; Matthews, E. Global inundation dynamics inferred from multiple satellite observations, 1993-2000. J. Geophys. Res. 2007, 112, D12107.

12. Alsdorf, D.; Han, S.-C.; Bates, P.; Melack, J. Seasonal water storage on the Amazon floodplain measured from satellites. Remote Sens. Environ. 2010, 114, 2448-2456.

13. Lee, H.R.; Beighley, E.; Alsdorf, D.; Jung, H.C.; Shum, C.K.; Duan, J.; Guo, J.; Yamazak, D.; Andreadis, K. Characterization of terrestrial water dynamics in the Congo Basin using GRACE and satellite radar altimetry. Remote Sens. Environ. 2011, 115, 3530-3538.

14. Hess, L.L.; Melack, J.M.; Simonett, D.S. Radar detection of flooding beneath the forest canopy: A review. Int. J. Remote Sens. 1990, 11, 1313-1325.

15. Kasischke, E.S.; Bourgeau-Chavez, L.L. Monitoring South Florida wetlands using ERS-1 SAR imagery. Photogramm. Eng. Remote Sens. 1997, 33, 281-291.

16. Kasischke, E.S.; Smith, K.B.; Bourgeau-Chavez, L.L.; Romanowicz, E.A.; Brunzell, S.; Richardson, C.J. Effects of seasonal hydrologic patterns in South Florida wetlands on radar backscatter measured from ERS-2 SAR imagery. Remote Sens. Environ. 2003, 88, 423-441. 
17. Frappart, F.; Seyler, F.; Martinez, J.-M.; Leon, J.G.; Cazenave, A. Floodplain water storage in the Negro River basin estimated from microwave remote sensing of inundation area and water levels. Remote Sens. Environ. 2005, 99, 387-399.

18. Arnesen, A.S.; Silva, T.S.F.; Hess, L.L.; Novo, E.M.L.M.; Rudorff, C.M.; Chapman, B.D.; McDonald, K.C. Monitoring flood extent in the lower Amazon River floodplain using ALOS/PALSAR ScanSAR images. Remote Sens. Environ. 2013, 130, 51-61.

19. Rosenqvist, A.; Shimada, M.; Chapman, B.; Freeman, A.; De Grandi, G.; Saatchi, S.; Rauste, Y. The Global Rain Forest Mapping project-A review. Int. J. Remote Sens. 2000, 21, 1375-1387.

20. Farr, T.G.; Rosen, P.A.; Caro, E.; Crippen, R.; Duren, R.; Hensley, S.; Kobrick, M.; Paller, M.; Rodriguez, E.; Roth, L.; et al. The Shuttle Radar Topography Mission. Rev. Geophys. 2007, 45, doi:10.1029/2005RG000183.

21. NASA Ames Advanced Supercomputing Division. Available online: http://www.nas.nasa.gov (accessed on 15 April 2014).

22. Rosenqvist, A.; Shimada, M.; Ito, N.; Watanabe, M. ALOS PALSAR: A pathfinder mission for global-scale monitoring of the environment. IEEE Trans. Geosci. Remote Sens. 2007, 45, 3307-3316.

23. Rosenqvist, A.; Shimada, M.; Watanabe, M. ALOS PALSAR: Technical outline and mission concepts. In Proceedings of the 4th International Symposium on Retrieval of Bio- and Geophysical Parameters from SAR Data for Land Applications, Innsbruck, Austria, 16-19 November 2004.

24. Shuttle Radar Topography Mission. Available online: http://www2.jpl.nasa.gov/srtm (accessed on 22 January 2015).

25. Rodriguez, E.; Morris, C.S.; Belz, J.E.; Chapin, E.C.; Martin, J.M.; Daffer, W.; Hensley, S. An Assessment of the SRTM Topographic Products; Technical Report JPL D-31639; Jet Propulsion Laboratory: Pasadena, CA, USA, 2005; p. 143.

26. Rosenqvist, A.; Shimada, M.; Chapman, B.; McDonald, K.; De Grandi, G.; Jonsson, H.; Williams, C.; Rauste, Y.; Nilsson, M.; Sango, D.; et al. An overview of the JERS-1 SAR Global Boreal Forest Mapping (GBFM) project. In Proceedings of the 2004 IEEE International Symposium on Geoscience and Remote Sensing (IGARSS'04), Anchorage, AK, USA, 20-24 September 2004.

27. Kawanishi, T.; Sezai, T.; Ito, Y.; Imaoka, K.; Takeshima, T.; Ishido, Y.; Shibata, A.; Miura, M.; Inahata, H.; Spencer, R.W. The Advanced Microwave Scanning Radiometer for the Earth Observing System (AMSR-E), NASDA's contribution to the EOS for global energy and water cycle studies. IEEE Trans. Geosci. Remote Sens. 2003, 41, 184-194.

28. NOAA Office of Satellite and Product Operations. Available online: http://www.ospo.noaa.gov/ Products/land/smops/sensors_AMSRE.html (accessed on 22 January 2015).

29. Ulander, L.M.H. Radiometric slope correction of synthetic-aperture radar images. IEEE Trans. Geosci. Remote Sens. 1996, 34, 1115-1122.

30. Shimada, M.; Isoguchi, O. JERS-1 SAR mosaics of Southeast Asia using calibrated path images. Int. J. Remote Sens. 2002, 23, 1507-1526.

31. Werner, C.; Wegmüller, U.; Strozzi, T.; Wiesmann, A. Gamma SAR and interferometric processing software. In Proceedings of the ERS-ENVISAT Symposium, Gothenburg, Sweden, 16-20 October 2000.

32. Gabriel, A.K.; Goldstein, R.M. Crossed orbit interferometry: Theory and experimental results from SIR-B. Int. J. Remote Sens. 1988, 9, 857-872. 
33. Shimada, M. Ortho-rectification and slope correction of SAR data using DEM and its accuracy evaluation. IEEE J. Sel. Top. Appl. Earth Obs. Remote Sens. 2010, 3, 657-671.

34. Lucas, R.; Armston, J.; Fairfax, R.; Fensham, R.; Accad, A.; Carreiras, J.; Kelley, J.; Bunting, P.; Clewley, D.; Bray, S.; et al. An evaluation of the ALOS PALSAR L-band backscatter-Aboveground biomass relationship Queensland, Australia: Impacts of surface moisture condition and vegetation structure. IEEE J. Sel. Top. Appl. Earth Obs. Remote Sens. 2010, 3, 576-593.

35. Martinez, J.-M.; Thuy Le, T. Mapping of flood dynamics and spatial distribution of vegetation in the Amazon floodplain using multitemporal SAR data. Remote Sens. Environ. 2007, 108, 209-223.

36. Telmer, K.H.; Costa, M.P.F. SAR-based estimates of the size distribution of lakes in Brazil and Canada: A tool for investigating carbon in lakes. Aquat. Conserv. Mar. Freshw. Ecosyst. 2007, 17, 289-304.

37. ESA GlobCover. Available online: http://due.esrin.esa.int/globcover (accessed on 15 April 2014).

38. LPDAAC. NASA Shuttle Radar Topography Mission Water Body Data Shapefiles \& Raster Files. Available online: https://pdaac.usgs.gov/products/measures_products_table/srtmswbd (accessed on 22 January 2015).

39. Chapman, B.; Siqueira, P.; Freeman, A. The JERS Amazon Multi-Season Mapping Study (JAMMS): Observation strategies and data characteristics. Int. J. Remote Sens. 2002, 23, 1427-1446.

40. Siqueira, P.; Chapman, B.; McGarragh, G. The creation and interpretation of the multiseason JERS-1 SAR mosaic over South America. Remote Sens. Environ. 2003, 87, 389-403.

41. Chapman, B.; Taylor, V.; Rosenqvist, A. Rain Forest Mapping Project to release CD-ROMs. EOS Trans. Am. Geophys. Union 1998, 79, 417.

42. Yongwei, S.; Alsdorf, D.E. Automated georeferencing and orthorectification of Amazon basin-wide SAR mosaics using SRTM DEM data. IEEE Trans. Geosci. Remote Sens. 2005, 43, 1929-1940.

43. Zhang, L.; Wu, W.; Zhou, Q.; Chen, Z.; Li, Z. Assess the accuracy of the Globcover cultivated land data in Northeast China. In Proceedings of the 2012 First International Conference on Agro-Geoinformatics (Agro-Geoinformatics), Shanghai, China, 2-4 August 2012.

44. Kalliola, R.; Puhakka, M.; Salo, J.; Tuomisto, H.; Ruokolainen, K. The dynamics, distribution and classification of swamp vegetation in Peruvian Amazonia. Ann. Bot. Fenn. 1991, 28, 225-239.

45. Schroeder, R.; Rawlins, M.; McDonald, K.C.; Podest, E.; Zimmermann, R.; Kueppers, M. Satellite microwave remote sensing of North Eurasian inundation dynamics: Development of coarse-resolution products and comparison with high-resolution synthetic aperture radar data. Environ. Res. Lett. 2010, 5, 015003.

46. JPL Wetlands Website. Available online: http://wetlands.jpl.nasa.gov (accessed on 8 May 2014).

47. ASF Wetlands Portal. Available online: https://portal.asf.alaska.edu/wetlands (accessed on 8 May 2014).

(C) 2015 by the authors; licensee MDPI, Basel, Switzerland. This article is an open access article distributed under the terms and conditions of the Creative Commons Attribution license (http://creativecommons.org/licenses/by/3.0/). 